NBER WORKING PAPER SERIES

\title{
DOES CONTRACTING OUT INCREASE THE EFFICIENCY OF GOVERNMENT PROGRAMS? EVIDENCE FROM MEDICAID HMOs
}

\author{
Mark Duggan \\ Working Paper 9091 \\ http://www.nber.org/papers/w9091 \\ NATIONAL BUREAU OF ECONOMIC RESEARCH \\ 1050 Massachusetts Avenue \\ Cambridge, MA 02138 \\ August 2002
}

I am grateful to David Autor, Katherine Baicker, Laurence Baker, Charlie Brown, David Cutler, Tom DeLeire, Joseph Doyle, Martin Feldstein, Amy Finkelstein, Michael Greenstone, Jonathan Gruber, Deborah Healy, James Hines, Steven Levitt, James Poterba, Steven Rivkin, Karl Scholz, and to seminar participants at Chicago, Harvard, Michigan, MIT, UC-Denver, Wisconsin, and the NBER Public Economics and Health Care meetings for very helpful comments, to the National Institute on Aging for financial support, and to Daniel Egel and Kyung Park for outstanding research assistance. Thanks to the California Department of Health Services for giving me access to the data used in this paper. The views expressed herein are those of the authors and not necessarily those of the National Bureau of Economic Research.

(C) 2002 by Mark Duggan. All rights reserved. Short sections of text, not to exceed two paragraphs, may be quoted without explicit permission provided that full credit, including (C) notice, is given to the source. 
Does Contracting Out Increase the Efficiency of Government Programs?

Evidence from Medicaid HMOs

Mark Duggan

NBER Working Paper No. 9091

August 2002

JEL No. H51, H57, H72, I11, I18, L33

\begin{abstract}
State governments contract with health maintenance organizations (HMOs) to coordinate medical care for nearly 20 million Medicaid recipients. Identifying the causal effect of HMO enrollment on government spending and health care quality is difficult if, as is often the case, recipients have the option to enroll in a plan. To estimate the average effect of HMO enrollment, this paper exploits county-level mandates introduced during the last several years in the state of California that required most Medicaid recipients to enroll in a managed care plan. The empirical results demonstrate that the resulting switch from fee-for-service to managed care was associated with a substantial increase in government spending but no observable improvement in health outcomes, thus apparently reducing the efficiency of this large government program. The findings cast doubt on the hypothesis that HMO contracting has reduced the strain on government budgets.
\end{abstract}

\author{
Mark Duggan \\ Department of Economics \\ University of Chicago \\ 1126 E. 59th Street, Room 508 \\ Chicago, IL 60637 \\ and NBER \\ mduggan@midway.uchicago.edu
}




\section{Introduction}

A central issue in public finance concerns the desirability of contracting public services out to the private sector. Advocates of contracting out argue that private firms are more efficient and are more likely to offer a range of services that will allow each individual to get closer to her preferred bundle. Opponents assert that private firms reduce non-contractible quality and avoid unprofitable clients. As previous researchers have noted, the optimal public-private mix is likely to vary across government services, with an easy-to-monitor service like garbage collection a strong candidate for contracting out and national defense located at the opposite end of the spectrum (Shleifer, 1998).

Though the extent of private sector involvement has been growing for a number of government services in the U.S., perhaps the most striking recent change has been the increasing role of private managed care organizations in the government's Medicare and Medicaid programs. Rather than directly reimbursing hospitals, physicians, and other health care providers, the federal and individual state governments now contract with HMOs and similar managed care organizations to coordinate medical care for more than one-third of the 75 million beneficiaries of these two programs. In most cases, the managed care plans are paid a fixed amount each month per enrollee. This payment may vary with recipient characteristics but typically does not increase if the recipient's health deteriorates or if she receives intensive treatments.

This shift from fee-for-service to managed care was to some extent motivated by a desire to reduce both the level and the growth rate of expenditures in these two public programs. Taken together, Medicare and Medicaid now account for nearly $\$ 500$ billion in government spending and are projected to account for an increasing share of GDP in the U.S. as the population ages. While these two programs provide valuable insurance to two of society's most vulnerable groups - the elderly and the poor - the method of payment that Medicare and Medicaid have historically used introduces significant distortions in medical care purchase decisions. Because the fee-for-service system does not constrain health care utilization and program participants only face a fraction of the price of additional medical care, individuals are likely to consume some services that provide a benefit substantially below cost. 
If managed care plans have information about the value that their Medicare and Medicaid enrollees are likely to place on particular treatments, they may be well positioned to reduce medical care utilization while still providing valuable insurance against adverse health shocks. ${ }^{1}$ In the limit, the set of marginal services - those covered by fee-for-service but not under managed care - would yield no health benefit and thus medical care spending could decline with no change in individuals' health outcomes (though presumably with some decline in their utility). Depending on the extent of moral hazard in medical care purchase decisions, the government could potentially lower public medical spending by contracting with organizations that can constrain health care utilization and more accurately measure the costs and benefits of particular services.

There are three additional channels through which HMOs could lower health care spending and increase the efficiency of medical care. First, because their reimbursement does not increase in response to changes in the health of their enrollees, managed care organizations will have a financial incentive to keep their beneficiaries healthy. Thus plans may use their superior information about the benefits of health care treatments and lifestyle changes to encourage decisions that will lower future demand for medical care services. Additionally, plans may be able to negotiate lower input prices from medical care suppliers, with recent work showing that private managed care plans pay lower prices than their private fee-for-service counterparts for the same services (Cutler, McClellan, Newhouse, 2000). And finally, if the government contracts with from multiple managed care plans, then the resulting competition and the increase in the number of options that program participants have may lead to substantial improvements in medical care quality. For these reasons, it is possible that managed care plans can lower public medical spending while holding constant or improving health outcomes for beneficiaries of the Medicare and Medicaid programs.

While the set of arguments in favor of contracting with HMOs is extensive, other theoretically appealing hypotheses suggest that shifting Medicare and Medicaid recipients to managed care will either

\footnotetext{
${ }^{1}$ See Glied (2000), Miller and Luft (1997), and Cutler, McClellan, and Newhouse (2000) for more detailed discussions of the potential effects of managed care.
} 
increase government spending or adversely affect health outcomes and thus reduce program efficiency. Because each program insures approximately 40 million individuals, the federal and individual state governments are likely to have more market power than a typical HMO and may therefore be able to negotiate lower prices for medical care. Additionally, to the extent that there are increasing returns to scale in program administration, contracting with multiple plans will increase total administrative costs and reduce the fraction of spending devoted to medical care services. Third, the costs to the government will depend not just on the costs to the managed care organization but also on the extent to which plans markup their bids when competing for Medicaid HMO contracts. If the bidding process is not particularly competitive, then this markup could be substantial. And finally, because HMOs are reimbursed a fixed amount per recipient that depends on a limited set of observable characteristics, they may have an incentive to provide a mix of services that discourages some individuals from enrolling.

It is therefore largely an empirical question whether the shift from fee-for-service to managed care has increased the efficiency of these two large government programs. Medicare is a federally funded and administered program in which recipients have the option to enroll in an HMO but are not required to do so. Identifying the effect of managed care enrollment in this program is difficult for two reasons. First, because virtually all Medicare recipients can enroll in a managed care plan, it is difficult to reliably estimate a causal effect, as those who choose to enroll in a plan are likely to differ in unobservable ways from those who do not. Second, even if one looks at changes in a particular recipient's spending or health outcomes following a switch into or out of managed care, it is plausible that a change in health and thus in the demand for medical care services caused the change.

In contrast to the Medicare program, Medicaid is administered by state governments and there is substantial variation across states and localities in the rules that influence Medicaid managed care enrollment. Furthermore, many Medicaid recipients are required to enroll in an HMO. Thus both of the obstacles to identification are less of an issue for this program.

In this paper, I estimate the effect of HMO contracting by exploiting twenty county-level Medicaid mandates passed in the state of California during the 1990s that required more than 3.5 million 
Medicaid recipients to enroll in an HMO. This study represents the first attempt to utilize individual-level data to measure both the spending and the health outcome effects of such an ambitious shift in the insurance coverage of the Medicaid population. ${ }^{2}$ As a result of the mandates, the fraction of program participants enrolled in an $\mathrm{HMO}^{3}$ rose from $14 \%$ to $51 \%$. The number of Medicaid managed care plans varied across counties, but in all cases the state government paid HMOs a fixed amount per recipientmonth and the plans then paid health care providers for medical care services. Recipients continued to bear no financial cost for any services covered by Medicaid - both the deductible and the co-pay remained at zero. ${ }^{4}$

My first set of empirical results, which uses county-level data from 1993 to 2000, strongly suggests that the shift from fee-for-service to managed care was associated with a significant increase in government spending. Obtaining a reliable point estimate of the effect of HMO enrollment from the county-level data is difficult, however, because the groups affected by the mandates accounted for a relatively small share of total Medicaid spending. In most counties, welfare recipients were required to enroll in an HMO while the aged, blind, and disabled beneficiaries of the SSI program were not. While most Medicaid recipients are eligible through welfare (TANF / Cal Works), SSI recipients are several times more costly on average and account for the majority of program spending.

I therefore next use individual-level data to estimate the average expenditure effect of switching a fee-for-service Medicaid recipient into an HMO. Using a 5\% sample of nearly 300,000 welfare recipients

\footnotetext{
${ }^{2}$ A substantial body of research examines the effect of Medicaid managed care on measures of health care quality (see Kaiser (1995) for a review) though few focus on health outcomes. Recent exceptions include Levinson and Ullman (1998) and Kaestner, Dubay, and Kenney (2002), with both studies using infant health as the outcome variable of interest. Notable papers that estimate the effect of Medicaid managed care on government spending include Leibowitz, Buchanan, and Mann (1992), Buchanan, Leibowitz, and Keesey (1996), and Goldman, Leibowitz, and Buchanan (1998). All three of these studies have the advantage of random assignment, though each one examines just one pilot managed care plan. The current study considers the effect of nearly 50 HMOs for a substantially longer time period and also considers the effect of these plans on health outcomes.

${ }^{3}$ In the discussion that follows, I use the terms HMO and managed care plan interchangeably. It is worth noting that HMOs represent one particular type of managed care, but that other types of insurance would also be classified as managed care (e.g. primary care case management, preferred provider organization). Because all of the 44 plans that have contracts in counties with a mandate are most accurately classified as HMOs, I do not distinguish between HMOs and other plan types.

${ }^{4}$ See Ellis and McGuire (1993) and Newhouse (1996) for a discussion of the tradeoffs associated with different degrees of supply and demand-side cost-sharing.
} 
with at least one month of Medicaid eligibility between January of 1993 and December of 1999, my findings demonstrate that the average effect of the switch in enrollment induced by the mandates was to increase government spending by approximately $12 \%$. The expenditure effect of the mandate varied substantially across counties, with increases of more than $20 \%$ occurring in those counties that had relatively little pre-mandate managed care penetration and no increase in counties with one-third of their Medicaid recipients voluntarily enrolled in an HMO at the time of the mandate. There are a number of possible explanations for this heterogeneous effect, including pre-mandate selection of low-cost individuals by HMOs and a correlation between the extent of voluntary HMO enrollment and the competitiveness of the bidding process. I discuss this further below.

Whether the increase in government spending was associated with an improvement in health outcomes is the subject of the third empirical section. The findings there suggest that switching fee-forservice Medicaid recipients into HMOs reduced the avoidable hospitalization rate among children by approximately $30 \%$. But because similar declines were observed for other conditions unlikely to be affected by medical care quality (i.e. accidents), this finding appears not to reflect a real improvement in health but instead a change in treatment patterns. An analysis of infant health outcomes supports this conclusion, as infants born in affected counties following the passage of the mandates are no less likely to die or to be born at low birth weight.

Taken together, the results suggest that contracting with HMOs reduced the efficiency of California's Medicaid program. At a minimum, one can reject the hypothesis that the switch from feefor-service to managed care reduced the state government's spending below what it otherwise would have been. It is obviously unclear whether these results do generalize to other categories of Medicaid recipients, to other state Medicaid programs, or to the federal Medicare program. But given that the mandates did mitigate the selection problem and that California's HMO market is among the most competitive in the U.S., the expenditure results described below should give pause to those who believe that HMO contracting is the most effective way to control current and future public medical spending. 
The outline of the paper is as follows. The second section presents a simple theoretical framework for identifying the effect of contracting out a government program. Section three provides background on the Medicaid program and on the mandates introduced during the last several years that have required most Medicaid recipients to enroll in an HMO. The fourth section presents both county and individual-level analyses that examine the impact that switching Medicaid recipients from the fee-forservice system to HMOs had on government spending. In section five I explore whether the growth in managed care was associated with a significant change in health outcomes. The final section concludes and discusses whether the findings presented here are likely to generalize to other settings.

\section{Theoretical Framework}

Consider a government program that provides medical insurance to $\mathrm{N}$ individuals by reimbursing $\mathrm{K}$ different types of providers (e.g.. physicians, hospitals, pharmacies, etc.) for the costs associated with each individual's medical care. Program participants do not bear any share of the costs for either type of service. For simplicity assume that each unit of service provided by a provider of type $\mathrm{k}$ is reimbursed at a price $\mathrm{P}_{\mathrm{k}}$. Under this program, total costs to the government of this fee-for-service program are:

$$
\text { (1) } C=\sum_{k=1}^{K} \sum_{j=1}^{N} P_{k} * X_{j k}\left(P_{1}, \ldots, P_{K}\right)+A_{F F S, N}
$$

with $\mathrm{X}_{\mathrm{jk}}$ equal to the units of medical care consumed by individual $\mathrm{j}$ at provider type $\mathrm{k}$ and $\mathrm{A}_{\mathrm{FFS}, \mathrm{N}}$ equal to the cost to the government of administering the program when there are $\mathrm{N}$ fee-for-service recipients. As $\mathrm{P}_{\mathrm{k}}$ increases, the average quality of service type $\mathrm{k}$ is likely to increase as health care providers compete to attract more program participants. Such an increase may also affect the equilibrium quality of the other services and is likely to influence the total amount of each service type consumed by program beneficiaries. For any vector of fee-for-service prices $P$ the health of individual $j$ will be $H_{j}(P)$, with the effect of prices on health potentially varying across individuals.

Now suppose that the government is considering contracting out medical care delivery for $n$ of the $\mathrm{N}$ program participants to a managed care organization. The government could begin by setting a 
level of health care quality that a managed care organization must meet or exceed, though there may be unobservable or non-contractible versions of quality that would make such a regulation difficult to enforce. Subject to a specific quality constraint, managed care organization $M$ would find it profitmaximizing to treat all $\mathrm{n}$ patients for an average reimbursement per program participant that is greater than or equal to a minimum amount $R_{M}$. The government could implement this by accepting bids from one or more private plans, accepting the lowest bid or the one with a particularly low price for its expected level of quality.

Because the number of fee-for-service recipients would decline and their average characteristics would potentially change, the government might simultaneously choose to adjust the fee-for-service vector of prices to $\widetilde{P}$. Total costs for the government would then be:

$$
\text { (2) } C=n R+\sum_{k=1}^{K} \sum_{j=n+1}^{N} \widetilde{P}_{k}^{*} X_{j k}\left(\widetilde{P}_{1}, \ldots, \widetilde{P}_{K}\right)+A_{F F S, N-n}+A_{M C, n}
$$

with $\mathrm{A}_{\mathrm{FFS}, \mathrm{N}-\mathrm{n}}$ equal to the costs of administering the smaller fee-for-service program, $\mathrm{A}_{\mathrm{MC}, \mathrm{n}}$ the corresponding cost for the managed care program, and $\mathrm{R}$ the per-recipient payment to the managed care plan. This equation demonstrates that the change in costs following the shift of $n$ program participants to a managed care organization will depend on three factors - the change in costs for the $\mathrm{n}$ managed care enrollees, the corresponding change for the N-n remaining fee-for-service recipients, and the change in total administrative costs $A_{F F S, N-n}+A_{M C, n}-A_{F F S, N}$. If the government does not change its fee-for-service prices and the supply of medical care services to the N-n fee-for-service participants is unaffected by the managed care contract, then only the first and third factors will influence the change in costs.

The cost to the managed care organization of coordinating medical care for the $\mathrm{n}$ program participants and ensuring that quality meets or exceeds the required amount will depend on the prices that they pay to each provider type and the number of units of each type of service that enrollees consume. In contrast to the government's role in the fee-for-service system, the managed care organization can 
directly affect the quantity of medical care consumed by choosing not to authorize services that are deemed cost-ineffective. Thus costs for the managed care organization will be equal to:

$$
\text { (3) } C_{M}=\sum_{k=1}^{K} \sum_{j=1}^{n} \hat{P}_{k}^{*} Z_{j k}\left(\hat{P}_{1}, \ldots, \hat{P}_{K}\right)+A_{M, n}
$$

with $\hat{P}$ equal to the vector or prices that the managed care organization pays to health care providers, $\mathrm{Z}_{\mathrm{jk}}$ representing the number of units of type $k$ that are consumed by individual $j$, and $A_{M, n}$ the costs of administering the program. For three reasons, the managed care plan's costs of coordinating medical care for the $\mathrm{n}$ program participants may differ from the corresponding cost for the government. The most obvious reason is that the managed care plan may reduce medical care utilization. Additionally, plans may negotiate prices with the K provider types that are quite different from the government's fee-forservice prices. And finally, the costs of administering the program may also differ across the two types of plans.

One final factor that will influence the expenditure effect of contracting with managed care organizations is the difference between the contractual amount $R$ and the average cost $\left(C_{M} / n\right)$. If plans mark up their bids substantially above expected average cost, then it may prove to be more costly to contract with a managed care organization, even if their costs are equal to or lower than the government's.

The preceding discussion assumes that quality is perfectly observable and that the government writes the contract holding the minimum level of health care quality constant. An alternative and equally plausible view would be that the government sets spending and then allows plans to submit bids based on quality. In reality, both spending and quality are jointly set in a typical contract, and some elements of quality may not be contractible. Thus one must examine the change in both government spending and health outcomes when assessing the desirability of contracting with managed care organizations.

Ideally, one would trace out the full relationship between spending and health outcomes for both fee-for-service and managed care, as it is possible that fee-for-service yields better health outcomes for certain levels of spending while managed care is more efficient for others. Because there is little 
exogenous variation in spending within either fee-for-service or managed care that would permit a reliable estimation of this relationship, the goal of the subsequent empirical work is more modest. In it, I estimate the change in government spending and health outcomes associated with the observed switch from fee-for-service to managed care, essentially picking one point on each of the two spending-health curves.

\section{Medicaid Managed Care Background and Empirical Framework}

California's Medicaid program currently provides health insurance to nearly 6.5 million lowincome individuals. Program participants are a diverse group, including newborn infants, the institutionalized elderly, and individuals in dozens of other Medicaid eligibility categories. Until the early 1990s, the vast majority of program participants were enrolled in a fee-for-service program, with the state of California directly reimbursing hospitals, physicians, pharmacies, and other health care providers for the costs associated with their medical care.

Perhaps because of dissatisfaction with the fee-for-service system, the state of California recently shifted to contracting with HMOs to coordinate care for more than half of the state's Medicaid recipients. From 1991 to 1999, the share of Medicaid recipients enrolled in a managed care plan increased from less than $12 \%$ to more than $51 \%$. As Table 1 demonstrates, this increase tracked the national increase quite closely, with the corresponding figures for the U.S. as a whole standing at $10 \%$ in 1991 and 56\% in 1999. Under this system, HMOs that contract with the state of California to coordinate medical care for Medicaid recipients are paid a fixed amount per recipient-month that varies across Medicaid eligibility categories.

While the growth at the state level proceeded quite smoothly during this time period, there was substantial variation across local market areas in the pace of managed care penetration. This variation was primarily driven by differences across counties in the timing of Medicaid managed care legislation. Beginning with Sacramento in April of 1994 and most recently with Monterey in October of 1999, certain categories of Medicaid recipients in the state of California were required to enroll in an HMO. The 
groups affected by the mandates and the number of plans from which recipients could choose varied substantially across counties.

\section{A. The Three Models of Medicaid Managed Care}

There are three approaches that California has employed to shift its Medicaid recipients into managed care plans. In the first, which is referred to as Geographic Managed Care (GMC), the state government contracts with several commercial HMOs to coordinate care for Medicaid recipients. Plans initially applied by submitting a menu of prices at which they would be willing to insure each type of Medicaid recipient. The government then awarded contracts to the six or seven plans most likely to deliver high quality medical care at a low price, though the weight placed on quality and expenditure was not specified.

The first county to switch its Medicaid recipients to managed care under this model was Sacramento, where welfare recipients and several other categories of Medicaid recipients were required to enroll in a plan beginning in April of 1994 . Those affected by the mandate accounted for nearly $70 \%$ of Medicaid recipients but a smaller percentage of program spending. Aged, blind, and disabled Medicaid recipients were not required to join an HMO but had the option to do so, while a small share of recipients (i.e. non-resident aliens) were not allowed to enroll in a plan. At the time of the mandate, approximately $8 \%$ of welfare recipients were voluntarily enrolled in a managed care organization. This share increased steadily during the next several months, but never reached $100 \%$ (see Figure 1). There were three reasons for this. First, it typically took a few months for newly eligible Medicaid recipients to become enrolled in a plan. Second, foster children receiving welfare payments were not required to join a plan. And third, a small percentage of recipients were given waivers from the mandates and allowed to remain in the feefor-service system. Despite this, the increase from less than $10 \%$ to more than $80 \%$ in just six months was quite a significant change.

As shown in Figure 2, an even more sharp change in managed care penetration occurred in Solano, the first county to switch its recipients into a county-organized health system (COHS) during the 
time period of interest. ${ }^{5}$ Under this model, the not-for-profit, community-based HMO was reimbursed a fixed amount per recipient-month that varied by eligibility category. In contrast to Sacramento, recipients did not have a choice of plan in COHS counties. Additionally, the state government did not accept bids from commercial companies, instead deciding in advance to contract with one Medicaid-only HMO in each county. In addition to welfare recipients, the aged, blind, and disabled were required to enroll in the managed care plan. ${ }^{6}$

The final model of Medicaid managed care used in California involved competition between one commercial plan and one private not-for-profit, Medicaid-only HMO. In these "Two-Plan" counties, the state solicited bids from private companies and awarded a contract to just one of the plans. Alameda was the first county to switch its Medicaid recipients into managed care plans using this model. The resulting increase in the fraction of recipients enrolled in an HMO was significant (see Figure 3), though a bit less rapid than the increase in Sacramento. Welfare recipients were required to enroll in one of the two plans, though the aged, blind, and disabled had the option to join. Table 3A summarizes how each of the major categories of Medicaid recipients was affected in each type of county.

Table 3B lists the counties that introduced Medicaid managed care mandates during the 1990s and the dates that each mandate was imposed. The final column gives the fraction of Medicaid recipients that were voluntarily enrolled in a managed care plan the month before the mandate took effect. If these voluntary HMO enrollees did systematically differ from those in fee-for-service at the time of the mandates, then the average effect of the mandate may have varied across counties. For example, if the typical plan selected healthier (low-cost) Medicaid recipients prior to a mandate, then one would, all else equal, observe a bigger post-mandate reduction (or smaller increase) in spending in counties with more voluntary HMO penetration because pre-mandate spending would be higher in these places.

It is theoretically ambiguous which of the three Medicaid managed care models would be more likely to yield a favorable change in government spending and health outcomes relative to the fee-for-

\footnotetext{
${ }^{5}$ Medicaid recipients in Santa Barbara and San Mateo were required to join a county-organized health system starting in 1983 and 1987, respectively. I select Solano as the first because my data do not begin until 1993.

${ }^{6}$ In most COHS counties, long-term care services are "carved out" of the managed care contracts.
} 
service system. For example, if market power allows the COHS plans to negotiate lower prices from health care providers, ${ }^{7}$ then one would expect to observe higher spending in GMC counties for the same level of quality. Alternatively, if the competitive bidding process in GMC counties leads plans to mark up their bids significantly less than their COHS counterparts, one would find significantly higher spending in COHS counties for the same level of quality. HMOs in Two-Plan counties will have more market power than those found in GMC counties, but may benefit less from the bidding process because the Medicaid-only HMO is guaranteed a contract and thus insulated from competition. ${ }^{8}$

Three additional points are worth emphasizing. First, the set of counties chosen for the mandates is by no means a representative sample of California's counties. Eighteen of the twenty largest counties in the state required Medicaid recipients to join an HMO while only three of the smallest thirty-eight disproportionately rural counties did. Part of the reason for this may be that HMOs already had a substantial presence in the larger counties but virtually none in the rural areas of the state. Second, the type of managed care chosen in each county was not random. Sacramento and San Diego were designated GMC counties by the state at least partly because the "safety net" providers there were not as reliant on Medicaid business as their counterparts in counties like Los Angeles and Riverside. And finally, the timing of the mandates is unlikely to have been strictly exogenous. It is therefore possible that policymakers passed the mandates precisely when health care spending was projected to accelerate or the average Medicaid recipient was becoming less healthy. All three of these issues should be considered when interpreting the subsequent empirical results.

\section{B. Medicaid Spending and Health Outcomes}

Those enrolled in a managed care plan typically have no paid fee-for-service claims. It is therefore not surprising that the increase in managed care enrollment has coincided with a decline in the relative importance of fee-for-service payments in the Medicaid program. In 1989, the $\$ 6.8$ billion in fee-

\footnotetext{
${ }^{7}$ It is worth noting that, even in COHS counties where there is just one plan, the HMOs have less market power than does the state Medicaid program because providers often have a presence in more than one county.

${ }^{8}$ I unfortunately do not have data on the number or the characteristics of losing bids in Two-Plan and GMC counties.
} 
for-service expenditures accounted for $73 \%$ of total Medicaid spending (see Table 2). This fraction declined to $53 \%$ by 1999 (64\% if hospital disproportionate share payments are included), with the corresponding shares for capitation payments increasing from $4 \%$ to $15 \%$. The first aim of this paper is to determine whether part of the slowdown in Medicaid spending during the last several years (from $16 \%$ annually in the $1989-93$ period to less than $5 \%$ per year during the sample period) was caused by the increase in HMO enrollment.

I begin by using annual, county-level data for the 1993 to 2000 time period to investigate whether expenditures changed significantly following the shift of Medicaid recipients from fee-for-service to managed care plans. I utilize the passage of a county managed care mandate as an instrumental variable to estimate the causal effect of switching Medicaid recipients into an HMO. The identifying assumption of this empirical approach is that the mandate is related to government spending only through its effect on plan enrollment. I discuss potential problems with this assumption below. The baseline empirical specifications are as follows:

$$
\begin{aligned}
& \text { (4) } \text { ManCare }_{k t}=\alpha_{1}+\gamma_{1} * \text { Mandate }_{k t}+\mu_{1} X_{k t}+\theta_{1 k}+\lambda_{1 t}+\varepsilon_{1 k t} \\
& \text { (5) } \text { Spending }_{k t}=\alpha_{2}+\gamma_{2} * \text { Mandate }_{k t}+\mu_{2} X_{k t}+\theta_{2 k}+\lambda_{2 t}+\varepsilon_{2 k t}
\end{aligned}
$$

with $\mathrm{k}$ and $\mathrm{t}$ indexing counties and years, respectively. The IV estimate of the effect of managed care enrollment on government spending is simply the ratio $\gamma_{2} / \gamma_{1}$.

The expenditure data in equation (5) includes county-specific fee-for-service, capitation, and disproportionate share hospital payments but exclude the other expenditure categories listed in Table 2, which together account for approximately $20 \%$ of California's Medicaid spending. Two of these categories - miscellaneous non fee-for-service and Medicare buy-in - are paid out almost exclusively on behalf of aged, blind, and disabled SSI recipients and thus are unlikely to be affected by mandates that differentially impacted welfare recipients. More importantly, these services are "carved out" of most managed care contracts for SSI recipients. Similarly, dental and community mental health services (covered by the Short-Doyle program) are also not included in the state's managed care contracts. As 
long as managed care coverage is not affecting payments to these other two types of providers, the absence of this data will not be problematic for the county level analysis.

The lack of data for the costs to the state of administering Medicaid for each county's Medicaid recipients is a cause for some concern. It is likely that the switch from fee-for-service to managed care affected the total cost to the state government of administering the program. Two opposing forces make the sign of this effect ambiguous. The state no longer disburses fee-for-service payments for most Medicaid recipients, but must now contract with and regulate a new set of organizations. The fact that administrative expenses continued to rise by $7 \%$ per year from 1993 to 1999 despite a $40 \%$ reduction in the number of individuals enrolled in the fee-for-service program suggests that the switch to managed care did not significantly reduce administrative costs for the state and may actually have increased them. Given these opposing forces and the fact that administrative costs account for less than $5 \%$ of total program spending, it seems unlikely that the absence of this data will have a significant impact on my estimates of the expenditure consequences of contracting with managed care organizations.

I then use a five percent sample of Medicaid recipients to estimate an analogous set of individuallevel regressions. The California Department of Health Services (DHS) maintains a database that contains all fee-for-service payments made on behalf of each Medicaid recipient. These claims include payments to hospitals, long-term care facilities, pharmacies, physicians, and many other types of health care providers. In a typical year, there are more than 150 million fee-for-service claims. Additionally, the DHS tracks each recipient's eligibility status in every month, and its eligibility file provides data on whether a recipient is enrolled in a managed care plan or is instead in the fee-for-service system. This eligibility data can be matched to another DHS data source that contains plan-specific reimbursement rates by month and Medicaid eligibility category. I use this information together with the fee-for-service claims to calculate individual-specific Medicaid spending for medical services received by the recipient in 
each year. My sample includes information for 634,284 individuals with at least one month of Medicaid eligibility between January of 1993 and December of $1999 .{ }^{9}$

There are two important advantages to using this individual-level managed care enrollment and expenditure data. First, it allows me to focus primarily on welfare recipients - the group that was differentially affected by the mandates - who are much less expensive than are recipients in other Medicaid eligibility categories. This is shown in the following table, which compares expenditures for three different categories of Medicaid recipients in the five percent sample in 1993. In all of the counties that introduced a Medicaid managed care mandate during the time period of interest, individuals eligible for welfare payments were required to enroll in an HMO. Recipients in the second largest major eligibility category - aged, blind, and disabled beneficiaries of the SSI program - had the option to join a plan but were not required to do so in most counties. Average costs per month for this group are approximately six times greater than for welfare recipients. ${ }^{10}$

\begin{tabular}{|c|c|c|c|}
\hline Eligibility Category & \# Eligible 1993 & Avg. Paid 1993 & Avg. Months 1993 \\
\hline All Recipients & 332,302 & 1613 & 9.4 \\
\hline Welfare & 197,698 & 718 & 9.6 \\
\hline Aged, Blind, Disabled & 65,228 & 4538 & 10.6 \\
\hline All Others & 69,376 & 1416 & 7.5 \\
\hline
\end{tabular}

Table A: 1993 Medicaid Expenditures by Eligibility Category

A second advantage of the individual-level data is that the county-level expenditure information was calculated by the state Medicaid agency based on the year of payment rather than the year that the service was received. A substantial share of spending in a year is made for services provided in previous years. For both reasons the individual-level data will allow me to more reliably isolate the effect of the increase in HMO enrollment induced by the mandate. ${ }^{11}$ To the extent that the mandates may have affected

\footnotetext{
${ }^{9}$ This implies that nearly 12.7 million Californians were eligible for Medicaid for one or more months during this seven-year period.

${ }^{10}$ The two most common group in the "all others" category are OBRA aliens and medically indigent children. The first group was not allowed to enroll in a managed care plan while the second group typically was.

${ }^{11}$ One limitation of the individual-level data is that I do not have person-specific disproportionate share hospital payments. Using the county level data, I test whether the absence of this information is likely to bias my individuallevel estimates of the expenditure effects of HMO contracting and find that it does not have an important effect on my county-level coefficient estimates.
} 
spending for other eligibility categories (i.e. the aged, blind, and disabled), the focus on welfare recipients will not be complete and thus the county-level specifications will have an advantage.

Once an individual enters a managed care plan, the Medicaid claims data is no longer informative about the individual's health status. It is therefore not possible to identify the effects of HMO enrollment on health care quality without a different source of data. In my analysis of health outcomes, I utilize hospital discharge data. Though the available data does not allow me to link a specific hospital patient with a particular Medicaid recipient, I can investigate whether average health outcomes changed in a county or zipcode following the passage of a managed care mandate. The specific outcomes used are described in section five below.

\section{The Effect of HMO Enrollment on Medicaid Spending}

In this section, I utilize both county and individual level Medicaid expenditure data to investigate whether government spending changed substantially following the shift of Medicaid recipients into HMOs. From January of 1993 to December of 1999, the fraction of Medicaid recipients enrolled in an HMO increased from $13 \%$ to $51 \%$. As Figure 4 demonstrates, the increase was even greater for welfare recipients, rising from $18 \%$ to $76 \%$ during the same time period. Virtually all of this increase was driven by the managed care mandates described above.

There are at least three channels through which HMOs could reduce medical care spending. First, managed care plans may reduce resource utilization by authorizing only those services that provide an expected benefit that is at or above the expected cost. Second, the plans may negotiate lower prices from medical care providers, with the potential savings depending both on the Medicaid fee schedule that was in place at the time of the mandates. And third, the HMO has a financial incentive to keep individuals healthy and may therefore encourage cost-effective preventive care and lifestyle changes that will reduce the future demand for health care services.

But there are other reasons to think that contracting with HMOs will lead to an increase in government expenditures. Most managed care organizations have fewer beneficiaries than the Medicaid 
program and thus may have less market power to negotiate low rates from providers. ${ }^{12}$ Additionally, the total costs of administering the program may increase as a result of the "partial privatization" of the program, with the government still administering a fee-for-service program and now having a new set of institutions to regulate. The HMOs must also pay to administer their Medicaid managed care programs and thus the fraction of Medicaid costs devoted to program administration could rise substantially. And finally, the costs to the government will depend not just on the costs to the managed care organization but also on the extent to which plans markup their bids when competing for Medicaid business. If the bidding process is not particularly competitive, then this markup could be substantial.

\section{A. County-Level Expenditure Effects of the Increase in HMO Enrollment}

To assess whether the introduction of the managed care mandates coincided with a significant change in government spending, I begin by running regressions analogous to (4) and (5) at the county level. The specifications in the county level regressions use observations for all 58 California counties in each year from 1993 to 2000 and include county and year fixed effects in all cases. Summary statistics for the variables used in this section are included in Table 4C.

The dependent variable in Table 4A is equal to the fraction of Medicaid eligible months in county $\mathrm{j}$ in year $\mathrm{t}$ in which recipients were enrolled in an HMO. The explanatory variable \% Mandated equals the fraction of Medicaid eligible months that were affected by the mandate. ${ }^{13}$ This variable will differ across counties for three reasons. First, at a point in time certain counties will have a mandate in effect while others will not. Second, the Medicaid eligibility categories required to join an HMO vary across counties. For example in COHS counties the aged, blind, and disabled are required to join a plan whereas in Two-Plan and GMC counties they are not. And finally, the distribution of Medicaid recipients across eligibility categories is not identical across counties. For example, a Two-Plan county with relatively

\footnotetext{
${ }^{12}$ A number of models predict that price discounts will increase with the market share of the buyer. See Stoles and Zwiebel (1996) for the case of a monopoly supplier and Snyder (1998) for an example with competing suppliers.

${ }^{13}$ Thus if there are 100 Medicaid recipients eligible for the entire year and 70 are required to join an HMO as of October 1 , the value for $\%$ Months Mandated will be $0.7 * 0.25=0.175$.
} 
many SSI recipients as a fraction of its Medicaid population will, all else equal, have a lower value for $\%$ Mandated than will another Two-Plan county with relatively few SSI recipients.

The statistically significant first-stage estimate of 0.563 demonstrates that the mandates induced a substantial increase in the share of Medicaid recipients enrolled in an HMO, though the relationship is not one-for-one for the reasons mentioned in the third section above. Including county-specific time trends in this regression does not affect the estimate substantially, which falls to 0.507 but remains statistically significant at the $1 \%$ level. A comparison of the estimates for the $\%$ Aged, Blind, and Disabled coefficient in the first two columns suggests that the specification with county time trends may be the more reliable one, as SSI recipients are much less likely to be in a managed care plan but the first specification suggests the opposite.

In the third and fourth specifications I interact the \% Mandated variable with the fraction of Medicaid recipients that were voluntarily enrolled in an HMO in the month before the mandate. If a fraction $\alpha$ of recipients are in a managed care plan at this time, then the maximum effect of the mandate on HMO enrollment is to increase this fraction by $1-\alpha$. As expected, the estimate for the $\%$ Mandated $*$ Initial coefficient is significantly negative and its inclusion leads to an increase in the estimate for the $\%$ Mandated coefficient, which rises to 0.78 .

Using these two variables as instrumental variables for managed care enrollment, I then investigate the relationship between the HMO enrollment induced by the mandates and county-level Medicaid spending in Table 4B. The first four columns use total spending per eligible as the dependent variable, while the latter four instead use the log of this value. The first two Spending specifications in columns (1) and (2) use only the \% Mandated variable as an instrument and yield conflicting estimates for the \% Managed Care coefficient. The difference between the two specifications is that the first one does not include county time trends while the second one does. The inclusion of these trends causes the estimate to change from small in magnitude and insignificantly negative to significantly positive. A similar pattern is observed for the Log (Spending) specifications in the fifth and sixth columns. Thus 
even if one accepts the assumption that the mandates provide plausibly exogenous variation in managed care enrollment, it is clearly difficult from this first set of specifications to determine the magnitude or even the sign of the expenditure effect.

In the next set of specifications, I use both the \% Mandated variable and its interaction $\%$ Mandated * Initial to instrument for HMO enrollment. The inclusion of this variable allows the average effect of the mandates to vary across counties depending on what share of recipients were initially in a managed care plan. If the expenditure effect of HMO enrollment is similar across individuals then one would expect to observe a smaller change in spending in counties with relatively many already enrolled when the mandate takes effect. By adding this second instrument, the estimates for the specifications with and without county time trends are much closer in magnitude and both are significantly positive. A similar pattern is observed for the analogous Log (Spending) specifications, though only one of the two is significant.

It therefore appears from this first set of results that the mandates were associated with a significant increase in government spending, though the results are not fully conclusive. It is worth noting that this effect, if properly estimated, could be driven by a number of different factors. For example, the state may have paid HMOs more for the groups that were required to enroll. Alternatively, plans may have selected relatively healthy individuals among the groups that were allowed, but not required, to join an HMO and thus expenditures may have increased due to imperfect risk adjustment. It is also possible that the state increased provider reimbursement rates to ensure continued access for feefor-service participants, who would now represent a smaller share of the market. And finally, fee-forservice providers may have increased the intensity with which they treated those remaining in the system if managed care plans contracted with new providers and the fee-for-service providers tried to compensate for their loss in income. I focus on the first of these four channels in the next section but all are potentially relevant for a reliable estimate of the full expenditure effect of the HMO mandates.

One potential concern with this set of specifications is that it includes California counties that have never required their Medicaid recipients to enroll in managed care plans. These areas are smaller, 
less densely populated places that may not represent appropriate controls for the larger urban counties that introduced managed care. In a separate set of specifications not reported here I show that excluding the 37 counties without a mandate does not have an important effect on my estimates. Additionally, because my subsequent individual-level analyses do not include hospital disproportionate share payments, I run the identical set of county-level specifications excluding these expenditures from the analysis. The results are quite similar to the ones reported here (see Appendix Table 1).

In Table 5A I replicate the specifications summarized in Table 4A but differentiate between the three types of HMO mandates that were introduced in California. The first specification suggests that the mandates had the sharpest effect on HMO enrollment in those counties that shifted recipients into countyorganized health systems. This is consistent with the graphs of managed care enrollment in the three "pioneer" counties described in section three. While Solano's HMO enrollment (in the COHS) increased from $1 \%$ to $100 \%$ in just one month, the increase was slower in both Sacramento (GMC) and Alameda (two-plan) counties. The negative coefficient estimate for the fraction of Medicaid recipients who are aged, blind, and disabled has the expected sign and is statistically significant at the 10 percent level. The estimates are not significantly affected by the inclusion of county-specific time trends but all three estimates increase when I control for the pre-mandate managed care enrollment.

In Tables 5B and 5C I attempt to estimate the difference in the expenditure effect across the three different types of counties. Theoretically, one might expect to observe a heterogeneous effect if the number of enrollees affected the plans' bargaining power with providers, if the difference in competitive bidding had an impact on plan markups, if there were increasing returns to scale in program administration, or if the possibility that an enrollee would switch to another managed care plan weakened the incentive to reduce expected future health care utilization. Of course given that the model of managed care selected for each county was not exogenous one would worry whether any difference was caused by this omitted variable rather than by the number of plans. But given the limited precision of both the reduced form and the IV estimates reported in these two tables, it is not possible to accurately measure 
this difference. This is perhaps not surprising given that there are relatively few counties in each plan type (2 GMC, 7 COHS, 12 Two-Plan) but I return to this issue below using the individual-level data.

Because the groups required to join an HMO in most counties accounted for a relatively small share of Medicaid expenditures, filtering out the signal from the noise in the county-level regressions is clearly difficult. In the section that follows, I use individual-level data and focus on welfare recipients to estimate the average effect of HMO enrollment on Medicaid expenditures. Focusing on the group directly affected by the mandate will obviously not provide a complete picture of the true effect, as there may be spillover effects and groups allowed but not required to join may experience a change in spending because of imperfect risk adjustment or some related factor. Nevertheless, this will allow me to more reliably and precisely estimate the effect of switching a Medicaid recipient from fee-for-service to an HMO on government spending. ${ }^{14}$

\section{B. Individual-Level Expenditure Effects of the Increase in HMO Enrollment}

In each of the 21 counties with a managed care mandate currently in place, welfare recipients are required to join an HMO. ${ }^{15}$ Table 6A demonstrates that the increase in HMO enrollment among welfare recipients in COHS, GMC, and 2-plan counties from 1993 to 1999 has been substantial. While just 20\% of welfare recipients in these 21 counties were enrolled in an HMO in January of 1993, more than 85\% were by December of 1999. During this same time period, HMO enrollment among welfare recipients in the other 37 counties remained at just $1 \%$.

In this section, I focus on a sample of individuals who are eligible for Medicaid in at least one month between January of 1993 and December of $1999 .{ }^{16}$ Additionally, I include in the sample only

\footnotetext{
${ }^{14}$ If, for example, there are spillover effects that cause expenditures for groups supposedly unaffected by the mandates to experience significant increases following the passage of the mandates. See Baker (1997) for an example of the spillover effects of Medicare HMOs on treatment and expenditures for fee-for-service recipients.

${ }^{15}$ This group of Medicaid recipients includes 33 Medicaid eligibility categories. Some of the individuals are not receiving welfare payments in each eligibility month. For example, as a result of the stricter welfare rules enacted during the 1990s, the state extended Medicaid benefits for many individuals whose welfare benefits were terminated. Foster children on welfare (approximately $2 \%$ of the welfare sample) are only required to join an HMO in COHS counties.

${ }^{16}$ Individuals are included in or excluded from the sample based on the last two digits of their social security number. For the $12 \%$ of recipients without a valid SSN, the last two digits of the unique Medicaid identifier are used.
} 
those individuals who are eligible for Medicaid through current or recent welfare receipt (i.e. not SSI, Medically Indigent, OBRA alien, etc.) in all of their eligible months during this period. This sample will therefore consist of the group of Medicaid eligible individuals whose HMO enrollment is most likely to have been affected by the managed care mandates. Of the 634,284 individuals with at least one month of Medicaid eligibility between 1993 and 1999, my sample includes 302,285 individuals. Of the remaining 331,999 people in the five percent sample, 243,074 have exactly zero months of eligibility through TANF / Cal Works while 88,925 have some - but not all - of their Medicaid eligibility months due to welfare receipt. Finally, I exclude 1907 individuals with data inconsistencies across years (i.e. male in 1993 but female in 1995) and drop the 21,393 individuals who live in San Diego during one or more months of their Medicaid eligibility because I do not have plan reimbursement rates for this county. I am then left with a sample of 278,985 Medicaid recipients.

An important feature of the Medicaid program is that spell lengths are often quite short and vary substantially across individuals. Figure 5 shows the distribution of the number of Medicaid eligible months in my five percent sample. More than $25 \%$ of the welfare recipients in the sample have 10 or fewer months of Medicaid eligibility and more than half have less than 30 months. There is a "spike" at 84 months of eligibility - for most of these individuals their spell is both right and left-censored. Additionally, some individuals in the sample have a break in eligibility, with $26 \%$ having two or more distinct spells during the 84 month time period.

In the empirical work that follows, I use individual-level data and take a recipient-year as the unit of observation to estimate the effect of the managed care mandates on government spending, weighting each observation by the number of months that the individual is eligible for Medicaid during the year. Because of heterogeneity in the number and duration of Medicaid eligibility spells, the number of observations varies across individuals. This distribution is shown in Table $6 \mathrm{~B}$, and my sample has more than 1.04 million person-year observations.

The key identifying assumption of my empirical approach is that the mandates affect Medicaid spending only through an impact on HMO enrollment. This assumption would be violated if, for 
example, the timing of the mandate in county $\mathrm{j}$ were systematically related to changes in spending that would have occurred in this county, relative to the rest of the state, in the absence of the mandate. It is not possible to rule out this type of legislative endogeneity, though because the date of each mandate varied substantially across counties and was typically chosen far in advance by the state government, this seems like a reasonable assumption. Furthermore, fee-for-service reimbursement rates for many providers, including physicians and pharmacies, were set at the state, and not at the provider level. This uniformity across market areas limits the potential for policy-makers in the state government to have forecasted when expenditures would increase in a specific county relative to the rest of California.

The results from specifications that explain the effect of the mandates on managed care enrollment are presented in Table 7A. In each specification, both year and 278,985 individual-specific fixed effects are included. In this set of specifications, the $\%$ Mandated variable is equal to the fraction of the person's eligible months in which they are required to be in a managed care plan. As was true in the county level regressions, the mandates are associated with a significant increase in HMO enrollment, and the estimated effect increases after controlling for the share of the county's welfare recipients that were enrolled in a managed care plan immediately before the mandate took effect. Specifications (2) and (4) control for the year that the person first appears in the data and interacts this variable with year dummies. Individuals initially appearing in 1993 and still eligible six years later may differ substantially from those appearing only in 1993 or who are first eligible in 1999. The inclusion of this set of interactions has virtually no impact on the coefficient estimates of interest.

The dependent variable in Table 7B is equal to total Medicaid expenditures for medical care services received by the recipient in the year. The reduced form specifications presented in the first and second columns suggest that the mandates were associated with an increase in government spending. According to the estimates from column (2), the average effect of the mandate was significantly lower in counties with a large share of recipients already enrolled in a plan. ${ }^{17}$ This pre-mandate cost difference

\footnotetext{
${ }^{17}$ The statistically significant point estimates of 138.1 and -399.6 on the $\%$ Mandated and $\%$ Mandated * Initial variables suggest that the average expenditure effect in counties with $35 \%$ of their recipients enrolled in an HMO at
} 
may have been driven by selection - HMOs attracted individuals healthier than the average and yet were reimbursed based on average costs - or simply because the counties initially paid rates to HMOs that were above average costs. Alternatively, counties with high voluntary managed care enrollment may have had a more efficient managed care market or experienced a more competitive bidding process for the post-mandate Medicaid contracts.

The results summarized in columns 3 and 4 utilize the \% Mandated variable to instrument for the share of eligible months that the person is enrolled in an HMO. The point estimates are positive and statistically significant using conventional standard errors, though insignificant after correcting for serial correlation in the error term. Because average spending per year has a mean of \$766 in 1999 dollars in this sample, the point estimates suggest that the HMO enrollment induced by the mandate is associated with a $12-14 \%$ increase in government spending.

In the final two specifications I allow the average expenditure effect of the mandate to vary across counties by using both the $\%$ Mandated and the $\%$ Mandated $*$ Initial variables as instruments for HMO enrollment. If the difference between HMO and fee-for-service costs does not vary significantly across counties, then one would expect the average effect of a mandate to differ if some counties initially had just $5 \%$ of their recipients in a managed care plan while others had $75 \%$, because the predicted increase in HMO enrollment in the latter county would be much smaller. The point estimates for the \% Managed Care variable increase substantially and suggest that switching a Medicaid recipient from fee-for-service to managed care was associated with more than a $20 \%$ increase in government spending.

In Table 7C I investigate whether the magnitude of the average expenditure effect did vary systematically across the different types of managed care mandates. Because I am missing data for one of the two GMC counties (San Diego) I group the other one (Sacramento) with the Two-Plan counties. The final specification summarized in this table suggests that the expenditure effect was not very different in COHS and Two-Plan counties, though the point estimate is somewhat larger for the former.

the time of the mandate was close to zero. Appendix Table 2 shows that Medicaid expenditure increases were largest in those counties that were closest to a pure fee-for-service system before the mandate. 
It therefore appears that the switch from fee-for-service to managed care has been associated with a substantial increase in government spending. The observed expenditure increase could have been driven by a number of different factors, though my data do not allow me to estimate the contribution of each factor to the increase. One plausible explanation is that managed care plans paid providers more than they received under Medicaid's fee-for-service systems. One of the largest COHS plans pointed out in a recent annual report that its physicians "receive 140 percent of the Medicaid fee schedule" (Cal Optima, 2000). Presumably plans must also expect to make a profit in order to willingly participate, and thus some of the additional spending may simply be accounted for by HMO net income. ${ }^{18}$ Additionally, imperfect competition in the bidding process or in the HMO market may have caused plans to mark up their bids substantially above cost. ${ }^{19}$ And finally, if there are economies of scale in program administration, then the state government may have a substantial per-recipient cost advantage as it can spread these costs over nearly seven million recipients each year.

While the results presented in this section cast considerable doubt on the hypothesis that managed care is responsible for the slowdown in Medicaid expenditure growth in the nation's most populous state, it says relatively little about the efficiency of the shift. In the next section, I explore whether the increase in HMO enrollment was associated with an observable improvement in health care quality, and then assess the efficiency effects of Medicaid HMO contracting.

\section{The Effect of HMO Enrollment on Health Outcomes}

There are a number of mechanisms through which HMOs could improve medical care quality for the poor. For example, plans have a financial incentive to keep their enrollees healthy to avoid future increases in expenditures. Additionally, HMOs may have better information about the quality of local medical care providers than low-income Medicaid recipients do. Third, competition between multiple plans will encourage HMOs to provide high quality medical care to attract potential customers. And finally, plans may use the additional revenues that they receive to give recipients access to better

\footnotetext{
18 This same COHS plan reported net income of more than $\$ 35$ million from capitation revenues of $\$ 570$ million.

${ }^{19}$ This may partially explain why counties with relatively little pre-mandate managed care penetration (and presumably less competitive HMO markets) saw the largest increases in government spending.
} 
providers than they would have in the fee-for-service system. Alternatively, short spell lengths on the program, incentives to select low cost patients while avoiding expensive ones, and plan dropout could reduce the benefits of contracting with HMOs.

In this section, I investigate whether the growth in HMO enrollment caused by the Medicaid managed care mandates led to a net improvement in health outcomes for the poor. The claims data described above have detailed information about each recipient's health status while in the fee-for-service system, but do not have comparable information once an individual enrolls in an HMO. I thus use a different data source that provides similar data for Medicaid recipients whether they are in a managed care plan or not. Specifically, I use hospital discharge data and administrative data on infant health to explore whether health outcomes for Medicaid recipients have improved as a result of the increase in HMO enrollment. I am unfortunately unable to link individual-level outcomes data with my Medicaid claims information, and therefore must aggregate outcome measures to the zipcode level. ${ }^{20}$

The first measure of health outcomes that I use is the number of avoidable hospitalizations among Medicaid-insured children. Previous studies have defined a set of conditions for which hospital admissions among children would fall if the quality of primary care increased (Parker and Schoendorf, 2000). ${ }^{21}$ If managed care organizations provide better medical care than individuals obtain under a feefor-service system, then it is plausible that health would improve as a result of this. Though I am unable to measure the amount of primary care that individuals receive, hospital discharge data does allow me to test whether an increase in HMO enrollment among Medicaid recipients is associated with a significant reduction in the hospitalization rate for avoidable conditions.

The regression results summarized in Table $8 \mathrm{~A}$ provide some insight into the importance of the shift from fee-for-service to HMOs. In these regressions, I use the information on zipcode of residence

\footnotetext{
${ }^{20}$ The state of California is currently constructing a data set that will enable researchers to perform this individuallevel link, but it is not yet available and will not cover the pre-mandate period in any of the 21 counties of interest.

${ }^{21}$ The list of conditions includes asthma, pneumonia, other upper airway conditions, gastroenteritis, dehydration, cellulites, and seizures. Dafny and Gruber (2002) use a slightly different measure of avoidable hospitalizations, which also includes diabetes and iron deficiency anemia. The most frequent diagnoses (e.g. asthma, pneumonia, gastroenteritis) are common to both lists.
} 
from the hospital discharge data and from the Medicaid claims data to construct variables at the zipcodeyear level. The first specification tests whether the HMO enrollment increases induced by the mandates are associated with a reduction in the avoidable hospitalization rate among Medicaid-insured children at the zipcode level, and account for the fact that the mandates are varying only at the county level when calculating the standard errors. The regressions include zipcode fixed effects to control for time-invariant differences across areas in health status or medical care practice patterns and year effects to control for average improvements in health among Medicaid recipients.

The dependent variable in the first column is equal to the $\log$ of the number of avoidable hospitalizations among Medicaid insured children in the zipcode-year. This set of conditions includes asthma, pneumonia, other upper airway conditions, gastroenteritis, dehydration, cellulitis, and seizures. The IV estimate for the \% Managed Care variable implies that the switch from fee-for-service to managed care induced a statistically significant $30 \%$ reduction in the avoidable hospitalization rate among Medicaid-insured children, though the precision of this estimate is not particularly high. Alternative measures of the dependent variable (i.e. the number of hospitalizations or hospitalizations per Medicaid recipient under the age of 15) yield similar results. ${ }^{22}$

This first result suggests that HMOs have improved the health of Medicaid recipients, perhaps by investing in preventive care and steering their enrollees to high quality health care providers when the return to doing so is substantial. But it is also consistent with the hypothesis that HMOs choose to hospitalize fewer individuals with a particular condition. I therefore test whether there is a similar decline in the hospitalization rate for external causes of injury (i.e. accidents, poisoning, etc.), a set of conditions that is unlikely to be affected by managed care organizations. The significantly negative estimate for the $\%$ Managed Care coefficient in the third column of Table 8A demonstrates that the decline for this other

\footnotetext{
${ }^{22}$ I include all avoidable hospitalizations (not just Medicaid) among children as the dependent variable in the second regression, to ensure that this first result is not simply driven by a "relabelling" effect, as hospitals could mistakenly code a Medicaid HMO patient as privately insured rather than Medicaid insured. The fact that the estimate remains negative and falls by approximately $50 \%$ suggests that this is not driving the results. Moreover, it implies that avoidable hospitalizations are not trending down among all children in the zipcodes with Medicaid managed care mandates but instead only among the Medicaid population.
} 
set of conditions has been similarly large, suggesting that the fall in medical care utilization is likely attributable to a change in treatment patterns rather than to a real improvement in health.

In Table 8B I examine whether infant health outcomes appear to have changed following the passage of the HMO mandates by estimating an analogous set of specifications for the fraction of infants born at low birth weight and the infant mortality rate. ${ }^{23}$ The advantage of this outcome measure is that all births occurring in California show up and thus it is easier to separately identify the health effect from the change in practice patterns. One disadvantage with this set of specifications is that I am unable to differentiate between Medicaid-insured infants and those with private insurance or without health insurance. If outcomes for these other groups are unaffected by and not systematically related with the mandates then this should not bias my findings, though it is important to keep in mind when interpreting the results.

The point estimates for the $\%$ Managed Care variable in the odd-numbered columns suggest virtually no relationship between the increase in managed care enrollment and the change in infant outcomes. If anything, average infant outcomes have gotten worse following the passage of the mandates, as all three point estimates are insignificantly positive. The even-numbered columns investigate whether the average change in health outcomes appears to vary across the three types of mandates. The positive and statistically significant point estimates in all three specifications for the \% Managed Care * GMC County coefficient indicate that infants born in GMC counties have worse outcomes now than they did prior to the mandates. The corresponding estimates for Two-Plan counties are much smaller in magnitude but insignificantly positive, while all three estimates for the COHS counties are negative.

One possible - but by no means the only - explanation for this pattern of results is that Medicaid recipients in GMC counties are less likely to be consistently enrolled in the same plan. Thus their medical care may frequently be disrupted as they switch from one plan to another. For example, 12\% of

\footnotetext{
${ }^{23}$ See Kaestner, Dubay, and Kenney (2001) for an examination of the effect of Medicaid managed care on infant health in the U.S. and Levinson and Ullman (1998) for an analysis of the Wisconsin experience. The results reported here are similar to the ones found in both of these studies, suggesting that Medicaid managed care does not have a significant impact on newborn outcomes.
} 
Medicaid recipients in GMC counties eligible throughout calendar year 1999 who were enrolled in a managed care plan in January had switched plans by December. The corresponding percentages for TwoPlan and COHS counties were $6 \%$ and $0.4 \%$, respectively. Having a choice between several different plans obviously has many potential advantages, but the costs may be greater if it substantially increases the ease with which HMOs can encourage unhealthy (and thus unprofitable) patients to leave their plan.

While this is by no means an exhaustive set of health outcomes and the aggregation of the data to the zipcode-year level prevents me from obtaining very precise coefficient estimates, the results presented in this section suggest that HMO contracting has not led to a substantial improvement in the quality of medical care received by California's Medicaid recipients.

\section{Discussion}

During the 1990s, the fraction of Medicaid recipients in the state of California enrolled in HMOs increased from less than $12 \%$ to more than $51 \%$. The results presented in this paper demonstrate that the increased reliance on HMOs led to a substantial increase in government spending and suggest that health outcomes for the poor did not improve significantly. It therefore appears that requiring millions of California's Medicaid recipients to switch out of the fee-for-service system and enroll in HMOs did not lead to an improvement in the efficiency of this government program.

Do the results for welfare recipients generalize to other Medicaid beneficiaries and to Medicaid programs in other states? Because the mandates differentially affected low cost Medicaid recipients, it is certainly possible that the impact for more expensive program participants with a different set of health conditions would not be similar. Additionally, fee-for-service Medicaid reimbursement rates in California are lower than those in the typical state. Thus it is possible that there is a greater chance of reducing government spending while simultaneously improving quality by contracting with HMOs in other state Medicaid programs.

But if policy makers chose not to require other Medicaid recipients (e.g. the aged, blind, and disabled receiving SSI) to enroll in a plan because they accurately forecasted that the efficiency effects for these other groups would be less favorable, then the results presented here provide may understate the 
extent to which HMO contracting would reduce program efficiency. Furthermore, because California's HMO market is the most mature in the nation, the managed care organizations in this state are presumably more efficient than the typical HMO. It is therefore ambiguous whether Medicaid HMO contracting would be more or less efficient in other states.

For two reasons, one may expect HMO contracting to be even less effective in the Medicare program. First, because recipients of this program have the option both to enroll in and to drop out of an $\mathrm{HMO}$, managed care organizations may find it more profitable to select healthy enrollees (conditional on observable characteristics) rather than to improve health. Second, the extent of demand-side cost sharing is much greater for fee-for-service recipients of this program than for their counterparts in Medicaid. Thus the fraction of expenditures that have relatively little value to the beneficiary is likely to be lower in Medicare.

The projected increases in public medical spending along with the deteriorating health of federal and state budgets may increase policy maker interest in contracting with HMOs. The results presented in this paper suggest that private managed care plans are unlikely to deliver cost savings to federal and state governments without reducing health care quality for Medicare and Medicaid recipients. 


\section{References}

Baker, Laurence, "The Effect of HMOs on Fee-For-Service Health Care Expenditures: Evidence from Medicare," Journal of Health Economics, 1997, 453-481.

Buchanan, Joan, Arleen Leibowitz, and Joan Keesey (1996), "Medicaid Health Maintenance Organizations: Can They Reduce Program Spending?” Medical Care, 34, 249-263.

Cutler, David, Mark McClellan, and Joseph Newhouse (2000), "How Does Managed Care Do It?" RAND Journal of Economics, 31, 526-548.

Dafny, Leemore, and Jonathan Gruber, "Does Public Insurance Improve the Efficiency of Medical Care? Medicaid Expansions and Child Hospitalizations," forthcoming, Journal of Public Economics.

Duggan, Mark (2000), "Hospital Ownership and Public Medical Spending," Quarterly Journal of Economics, 115, 1343-1374.

Ellis, Randall P. and Thomas McGuire (1993), "Supply-Side and Demand-Side Cost Sharing in Health Care," Journal of Economic Perspectives, 7, 135-151.

Glied, Sherry (2000) "Managed Care," in J.P. Newhouse and A.J. Culyer, eds., The Handbook of Health Economics. Amsterdam: North-Holland, 2000.

Goldman, Dana, Arleen Leibowitz, and Joan Buchanan (1998), "Cost-Containment and Adverse Selection in Medicaid HMOs," Journal of the American Statistical Association, 93, 54-62.

Kaestner, Robert, Lisa Dubay, and Genevieve Kenney (2002), "Medicaid Managed Care and Infant Health: A National Evaluation," NBER Working Paper 8936.

Kaiser Commission on the Future of Medicaid, 1995, "Medicaid and Managed Care: Lessons from the Literature," The Kaiser Commission, Washington, D.C.

Leibowitz, Arleen, Joan Buchanan, and Joyce Mann (1992), “A Randomized Trial to Evaluate the Effectiveness of a Medicaid HMO," Journal of Health Economics, 11, 235-257.

Levinson, Arik and Frank Ullman (1998), "Medicaid Managed Care and Infant Health," Journal of Health Economics, 17, 351-368.

Miller, R.H. and Hal Luft (1997), “Does Managed Care Lead to Better or Worse Quality of Care?" Health Affairs, 16, 7-25.

Newhouse, Joseph (1996), "Reimbursing Health Plans and Health Providers: Efficiency in Production versus Selection," Journal of Economic Literature, 34, 1236-1263.

Parker, Jennifer and Kenneth Schoendorf (2000), "Variation in Hospital Discharges for Ambulatory CareSensitive Conditions Among Children," Journal of the Ambulatory Pediatric Association, 106, 942-948.

Shleifer, Andrei (1998), "State Versus Private Ownership," Journal of Economic Perspectives, 133-150. 
Snyder, Chris, "Why Do Larger Buyers Pay Lower Prices? Intense Supplier Competition," Economics Letters, 58, 205-209.

Stole, Lars, and Jeff Zwiebel, "Intra-Firm Bargaining under Non-Binding Contracts," Review of Economic Studies, 63, 375-410. 

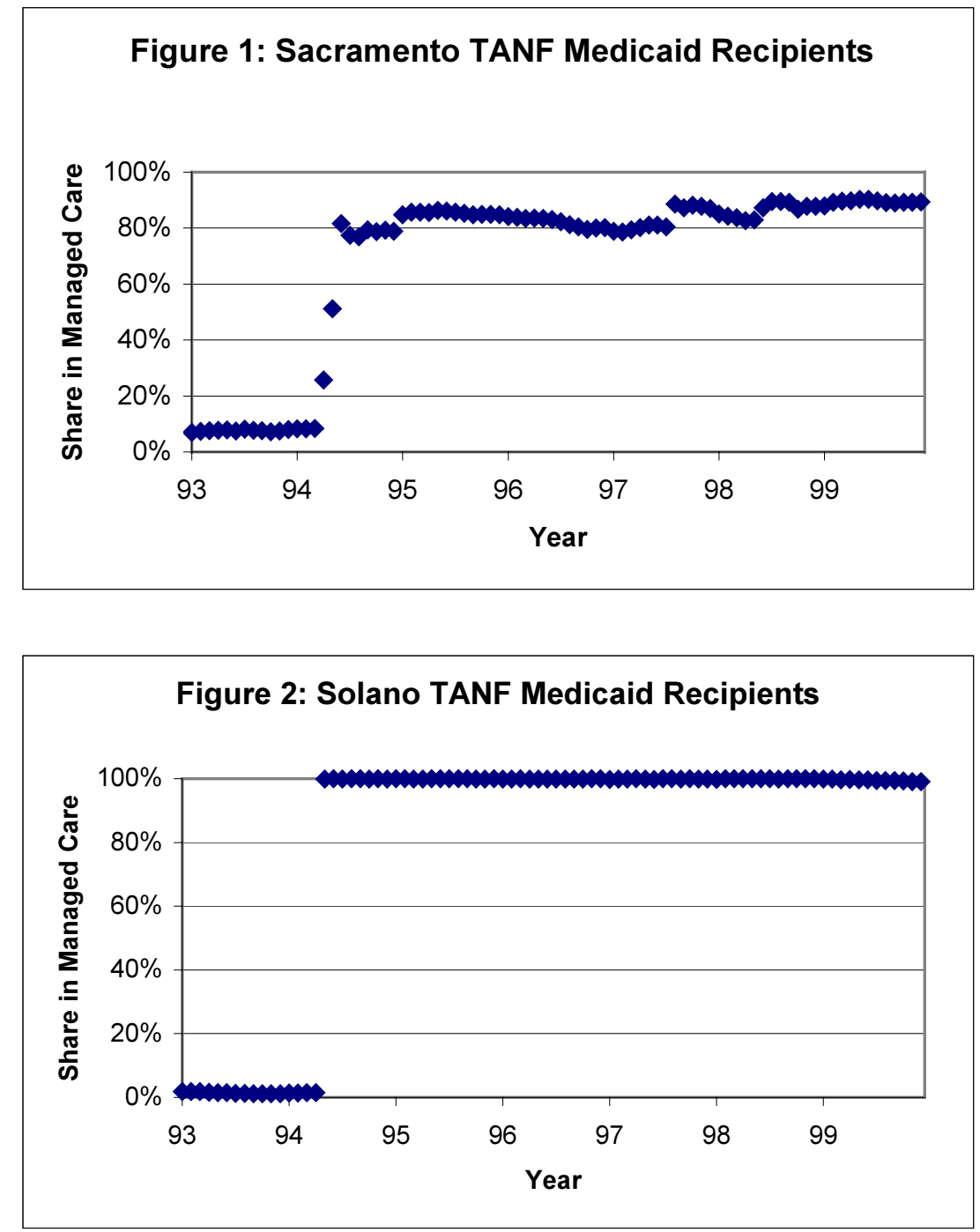

Figure 3: Alameda TANF Medicaid Recipients

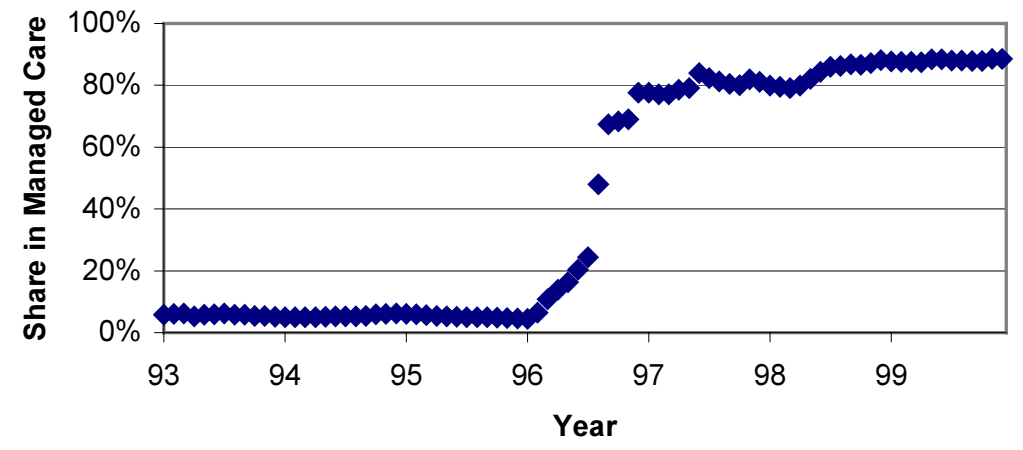


Figure 4: California TANF Medicaid Recipients

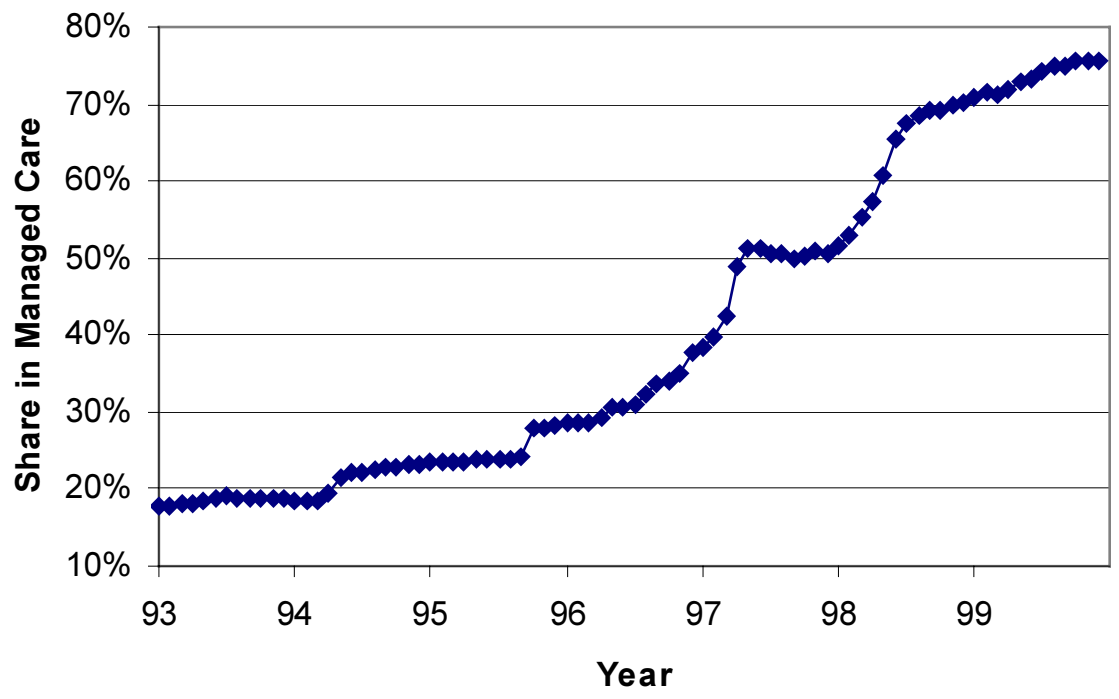

Figure 5: Months of Medicaid Eligibility 1993-99

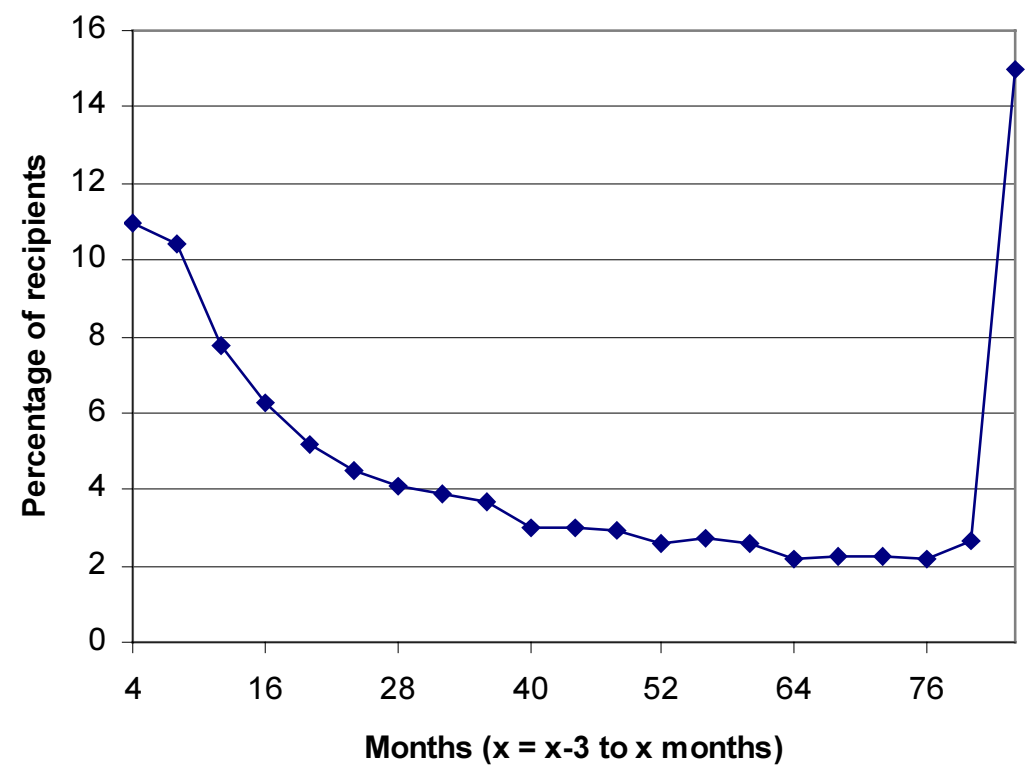


Table 1: Medicaid Managed Care Penetration Rates 1991-2000

\begin{tabular}{|c|c|c|c|c|}
\hline \multirow{2}{*}{ Year } & \multicolumn{2}{|c|}{ U.S. Medicaid } & \multicolumn{2}{c|}{ California Medicaid } \\
\cline { 2 - 5 } & \# Recipients & \% Man. Care & \# Recipients & $\%$ Man. Care \\
\hline 1991 & 28.3 & $9.5 \%$ & 4.02 & $11.7 \%$ \\
\hline 1992 & 30.9 & $11.8 \%$ & 4.49 & $12.5 \%$ \\
\hline 1993 & 33.4 & $14.4 \%$ & 4.83 & $14.1 \%$ \\
\hline 1994 & 33.6 & $23.2 \%$ & 5.01 & $16.3 \%$ \\
\hline 1995 & 33.4 & $29.4 \%$ & 5.02 & $23.5 \%$ \\
\hline 1996 & 33.2 & $40.1 \%$ & 5.11 & $23.1 \%$ \\
\hline 1997 & 32.1 & $47.8 \%$ & 4.79 & $38.7 \%$ \\
\hline 1998 & 30.9 & $53.6 \%$ & 4.90 & $45.8 \%$ \\
\hline 1999 & 31.9 & $55.6 \%$ & 4.97 & $51.1 \%$ \\
\hline 2000 & 33.7 & $55.8 \%$ & 5.04 & $50.1 \%$ \\
\hline
\end{tabular}

Data were obtained from HCFA publications and from www.hcfa.gov

Table 2: California Medicaid Expenditures in 1989, 1993, and 1999

\begin{tabular}{|c|c|c|c|}
\hline Category of Spending & $1988-89$ & $1992-93$ & $1998-1999$ \\
\hline FFS Provider Payments & 6820 & 10195 & 10526 \\
\hline Capitation Payments & 477 & 667 & 2962 \\
\hline Disproportionate Share Hospital & 0 & 2054 & 2154 \\
\hline Miscellaneous non-FFS & 94 & 280 & 1108 \\
\hline Administration & 297 & 633 & 971 \\
\hline Medicare Buy-In & 273 & 414 & 827 \\
\hline Dental & $147^{*}$ & 479 & 689 \\
\hline Short-Doyle / Medi-Cal & 119 & 244 & 614 \\
\hline Other and Recoveries & -19 & 9 & -80 \\
\hline Total & $\$ 8208$ & $\$ 14973$ & $\$ 19769$ \\
\hline Per California State Resident & $\$ 281$ & $\$ 480$ & $\$ 601$ \\
\hline
\end{tabular}

Values are in millions of 1999 dollars. 
Table 3A: Mandates by Plan Type and Medicaid Eligibility Category

\begin{tabular}{|c|c|c|c|}
\hline Aid Category & COHS & 2-plan & GMC \\
\hline AFDC / Cal-Works & Mandatory & Mandatory & Mandatory $^{* *}$ \\
\hline Aged, Blind, Disabled & Mandatory & Voluntary $^{* *}$ & Voluntary $^{* *}$ \\
\hline Medically Indigent Child & Mandatory & Mandatory & Mandatory \\
\hline OBRA Alien & Varies & Not eligible & Not eligible \\
\hline All Others & Varies & Varies & Varies \\
\hline
\end{tabular}

"Excludes foster children ${ }^{* *}$ Excludes long-term care

Table 3B: Type and Date of Managed Care Mandate by County

\begin{tabular}{|c|c|c|c|}
\hline County & Type of Mandate & Date of Mandate & Pre-Mandate \% MC \\
\hline Santa Barbara & COHS & $9 / 83$ & - \\
\hline San Mateo & COHS & $12 / 87$ & - \\
\hline Solano & COHS & $5 / 94$ & $1.0 \%$ \\
\hline Orange & COHS & $10 / 95$ & $0.0 \%$ \\
\hline Santa Cruz & COHS & $1 / 96$ & $0.0 \%$ \\
\hline Napa & COHS & $3 / 98$ & $0.0 \%$ \\
\hline Monterey & COHS & $10 / 99$ & $6.6 \%$ \\
\hline Sacramento & GMC & $4 / 94$ & $39.3 \%$ \\
\hline San Diego & GMC & $7 / 98$ & $3.3 \%$ \\
\hline Alameda & Two-Plan & $1 / 96$ & $0.7 \%$ \\
\hline San Joaquin & Two-Plan & $2 / 96$ & $0.0 \%$ \\
\hline Kern & Two-Plan & $7 / 96$ & $6.7 \%$ \\
\hline San Francisco & Two-Plan & $7 / 96$ & $21.3 \%$ \\
\hline Riverside & Two-Plan & $9 / 96$ & $23.9 \%$ \\
\hline San Bernardino & Two-Plan & $9 / 96$ & $2.9 \%$ \\
\hline Santa Clara & Two-Plan & $10 / 96$ & $3.3 \%$ \\
\hline Fresno & Two-Plan & $11 / 96$ & $15.4 \%$ \\
\hline Contra Costa & Two-Plan & $2 / 97$ & $0.0 \%$ \\
\hline Stanislaus & Two-Plan & $2 / 97$ & $26.8 \%$ \\
\hline Los Angeles & Two-Plan & $4 / 97$ & $0.0 \%$ \\
\hline Tulare & Two-Plan & $2 / 99$ & \\
\hline
\end{tabular}


Table 4A: The Effect of Mandates on Medicaid Managed Care Enrollment

\begin{tabular}{|c|c|c|c|c|}
\hline \multirow{2}{*}{} & \multicolumn{3}{|c|}{ \% Eligible Months in Managed Care } \\
\cline { 2 - 5 } & $(1)$ & $(2)$ & $(3)$ & $(4)$ \\
\hline \% Mandated & .563 & .507 & .775 & .778 \\
& $(.049)$ & $(.071)$ & $(.046)$ & $(.081)$ \\
& {$[.080]$} & {$[.097]$} & {$[.077]$} & {$[.110]$} \\
\hline \% Mandated * Initial & & & -1.392 & -1.961 \\
& & & $(.161)$ & $(.340)$ \\
& & & {$[.203]$} & {$[.350]$} \\
\hline \% Aged, Blind, Disabled & .136 & -1.439 & .190 & -.879 \\
& $(.422)$ & $(.994)$ & $(.337)$ & $(.640)$ \\
& {$[.774]$} & {$[1.039]$} & {$[.609]$} & {$[.688]$} \\
\hline \# Observations & 464 & 464 & 464 & 464 \\
\hline R-squared & .922 & .956 & .953 & .970 \\
\hline County Trends? & No & Yes & No & Yes \\
\hline
\end{tabular}

Sample includes county-year observations for California from 1993 to 2000. Dependent variable is equal to the share of eligible months in which Medicaid recipients are enrolled in a managed care plan. Robust standard errors are included in parentheses, and those reported in brackets are clustered by county to control for serial correlation in the error term. Regressions include county and year fixed effects and are weighted by the share of Medicaid eligible months in a year accounted for by each county.

Table 4B: IV Estimates of Effect of Managed Care Enrollment on Medicaid Expenditures

\begin{tabular}{|c|c|c|c|c|c|c|c|c|}
\hline & \multicolumn{4}{|c|}{ Spending per Eligible } & \multicolumn{4}{c|}{ Log (Spending per Eligible) } \\
\cline { 2 - 9 } & $(1)$ & $(2)$ & $(3)$ & $(4)$ & $(5)$ & $(6)$ & $(7)$ & $(8)$ \\
\hline \% Managed Care & -39 & 296 & 180 & 258 & -.038 & .099 & .040 & .084 \\
& $(106)$ & $(108)$ & $(90)$ & $(92)$ & $.043)$ & $(.045)$ & $(.034)$ & $(.040)$ \\
& {$[183]$} & {$[140]$} & {$[136]$} & {$[111]$} & {$[.070]$} & {$[.046]$} & {$[.047]$} & {$[.038]$} \\
\hline \% ABD & 8760 & 9388 & 8732 & 9340 & 2.281 & 2.873 & 2.271 & 2.854 \\
& $(1081)$ & $(802)$ & $(1086)$ & $(785)$ & $(.428)$ & $(.284)$ & $(.431)$ & $(.275)$ \\
& {$[1873]$} & {$[1233]$} & {$[1905]$} & {$[1195]$} & {$[.756]$} & {$[.424]$} & {$[.776]$} & {$[.401]$} \\
\hline \# Observations & 464 & 464 & 464 & 464 & 464 & 464 & 464 & 464 \\
\hline County Trends? & No & Yes & No & Yes & No & Yes & No & Yes \\
\hline DSH \$ included? & Yes & Yes & Yes & Yes & Yes & Yes & Yes & Yes \\
\hline IV used & 1 & 1 & $1 \& 2$ & $1 \& 2$ & 1 & 1 & $1 \& 2$ & $1 \& 2$ \\
\hline
\end{tabular}

Sample includes county-year observations for California from 1993 to 2000. Dependent variable in the first four (last four) specifications is equal to (the log of) Medicaid spending (in 2000 dollars) per eligible. Specifications in columns 1,2,5,6 use \% Mandated as an IV, while those in the remaining four columns use both \% Mandated and \% Mandated * Initial. Robust standard errors are included in parentheses, and those reported in brackets are clustered by county to control for serial correlation in the error term. Regressions include county and year fixed effects and are weighted by the share of Medicaid eligible months in a year accounted for by each county. 
Table 4C: Summary Statistics

\begin{tabular}{|c|c|c|}
\hline & Mean & Std. Dev. \\
\hline \% Managed care & .311 & .247 \\
\hline \% Mandated & .305 & .326 \\
\hline \% Mandated * Initial & .047 & .067 \\
\hline \% Aged, Blind, Disabled & .245 & .056 \\
\hline Spending per Eligible & 2967 & 640 \\
\hline Spending per Eligible (no DSH) & 2528 & 534 \\
\hline Log (Spending per Eligible) & 7.97 & .215 \\
\hline Log (Spending per Eligible (no DSH)) & 7.82 & .198 \\
\hline \% COHS Mandated & .059 & .223 \\
\hline \% GMC Mandated & .036 & .146 \\
\hline \% 2-Plan Mandated & .210 & .282 \\
\hline \% Managed Care * COHS County & .059 & .214 \\
\hline \% Managed Care * GMC County & .046 & .146 \\
\hline \% Managed Care * 2-Plan County & .206 & .208 \\
\hline
\end{tabular}

Table 5A: The Effect of Mandates on Managed Care Enrollment by Type of Plan

\begin{tabular}{|c|c|c|c|c|}
\hline \multirow{2}{*}{} & \multicolumn{4}{|c|}{ \% Eligible Months in Managed Care } \\
\cline { 2 - 5 } & $(1)$ & $(2)$ & $(3)$ & $(4)$ \\
\hline$\%$ COHS Mandated & .818 & .866 & .936 & 1.042 \\
& {$[.037]$} & {$[.041]$} & {$[.044]$} & {$[.071]$} \\
\hline$\%$ GMC Mandated & .555 & .565 & .878 & .934 \\
& {$[.173]$} & {$[.293]$} & {$[.060]$} & {$[.096]$} \\
\hline$\%$ 2-Plan Mandated & .449 & .313 & .665 & .569 \\
& {$[.064]$} & {$[.053]$} & {$[.052]$} & {$[.077]$} \\
\hline \% Mandated * Initial & & & -1.290 & -1.863 \\
& & & {$[.184]$} & {$[.257]$} \\
\hline \% Aged, Blind, Disabled & -.729 & -1.657 & -.619 & -1.269 \\
& {$[.417]$} & {$[.912]$} & {$[.483]$} & {$[.581]$} \\
\hline R-squared & .941 & .968 & .964 & .980 \\
\hline County Trends? & No & Yes & No & Yes \\
\hline
\end{tabular}

Sample includes county-year observations for California from 1993 to 2000. Dependent variable is equal to the share of eligible months in which Medicaid recipients are enrolled in a managed care plan. Robust standard errors are included in parentheses, and those reported in brackets are clustered by county to control for serial correlation in the error term. Regressions include county and year fixed effects and are weighted by the share of Medicaid eligible months in a year accounted for by each county. 
Table 5B: Reduced Form Estimates of Effect of Mandates on Medicaid Expenditures

\begin{tabular}{|c|c|c|c|c|}
\hline & \multicolumn{4}{|c|}{ Spending per Eligible } \\
\cline { 2 - 5 } & $(1)$ & $(2)$ & $(3)$ & $(4)$ \\
\hline \% COHS Mandated & 118 & 114 & 254 & 140 \\
& {$[114]$} & {$[162]$} & {$[97]$} & {$[154]$} \\
\hline \% GMC Mandated & 118 & 160 & 488 & 215 \\
& {$[125]$} & {$[54]$} & {$[168]$} & {$[101]$} \\
\hline \% 2-Plan Mandated & -103 & 163 & 144 & 201 \\
& {$[131]$} & {$[71]$} & {$[128]$} & {$[102]$} \\
\hline \% Mandated * Initial & & & -1480 & -275 \\
& & & {$[474]$} & {$[394]$} \\
\hline \% Aged, Blind, Disabled & 8044 & 8959 & 8171 & 9016 \\
& {$[1678]$} & {$[1075]$} & {$[1597]$} & {$[1110]$} \\
\hline R-squared & .955 & .984 & .960 & .984 \\
\hline County Trends? & No & Yes & No & Yes \\
\hline
\end{tabular}

Sample includes county-year observations for California from 1993 to 2000. Dependent variable is equal to Medicaid spending (in 2000 dollars) per eligible. Robust standard errors are included in parentheses, and those reported in brackets are clustered by county to control for serial correlation in the error term. Regressions include county and year fixed effects and are weighted by the share of Medicaid eligible months in a year accounted for by each county.

Table 5C: IV Estimates of Effect of Managed Care Enrollment on Medicaid Expenditures

\begin{tabular}{|c|c|c|c|c|}
\hline & \multicolumn{4}{|c|}{ Spending per Eligible } \\
\cline { 2 - 5 } & $(1)$ & $(2)$ & $(3)$ & $(4)$ \\
\hline \% Managed Care in & 138 & 102 & 233 & 109 \\
COHS Counties & {$[133]$} & {$[209]$} & {$[140]$} & {$[206]$} \\
\hline \% Managed Care in & 160 & 282 & 460 & 254 \\
GMC Counties & {$[195]$} & {$[282]$} & {$[227]$} & {$[222]$} \\
\hline \% Managed Care in & -203 & 519 & 144 & 369 \\
2-Plan Counties & {$[283]$} & {$[217]$} & {$[197]$} & {$[197]$} \\
\hline \% Aged, Blind, Disabled & 7969 & 9821 & 8390 & 9556 \\
& {$[1596]$} & {$[1292]$} & {$[1835]$} & {$[1228]$} \\
\hline IV Used & 1 & 1 & $1 \& 2$ & $1 \& 2$ \\
\hline County Trends? & No & Yes & No & Yes \\
\hline
\end{tabular}

Sample includes county-year observations for California from 1993 to 2000 . Dependent variable is equal to Medicaid spending (in 2000 dollars) per eligible. Specifications in columns 1 and 2 use \% Mandated* Type of Plan as instrumental variables, while those in columns 3 and 4 also use \% Mandated * Initial. Robust standard errors are included in parentheses, and those reported in brackets are clustered by county to control for serial correlation in the error term. Regressions include county and year fixed effects and are weighted by the share of Medicaid eligible months in a year accounted for by each county. 
Table 6A: Change in Managed Care Penetration Resulting from Mandates

\begin{tabular}{|c|c|c|c|c|}
\hline \multirow{2}{*}{ Type of Plan } & \multicolumn{2}{|c|}{ AFDC } & \multicolumn{2}{c|}{ Aged, Blind, Disabled } \\
\cline { 2 - 5 } & $1 / 93$ & $12 / 99$ & $1 / 93$ & $12 / 99$ \\
\hline COHS & $\begin{array}{c}29 \% \\
(n=13425)\end{array}$ & $\begin{array}{c}100 \% \\
(n=9744)\end{array}$ & $\begin{array}{c}26 \% \\
(n=5357)\end{array}$ & $\begin{array}{c}94 \% \\
(n=6600)\end{array}$ \\
\hline Two-Plan & $\begin{array}{c}19 \% \\
(n=107706)\end{array}$ & $\begin{array}{c}83 \% \\
(n=99448)\end{array}$ & $\begin{array}{c}3 \% \\
(n=38364)\end{array}$ & $\begin{array}{c}7 \% \\
(n=44657)\end{array}$ \\
\hline GMC & $\begin{array}{c}20 \% \\
(n=18749)\end{array}$ & $\begin{array}{c}88 \% \\
(n=15849)\end{array}$ & $\begin{array}{c}4 \% \\
(n=6439)\end{array}$ & $\begin{array}{c}12 \% \\
(n=7605)\end{array}$ \\
\hline Other 37 & $1 \%$ & $1 \%$ & $1 \%$ & $1 \%$ \\
$(n=18045)$ & $(n=14811)$ & $(n=7172)$ & $(n=7855)$ \\
\hline
\end{tabular}

AFDC category includes recipients who are receiving welfare (AFDC / TANF / CalWorks, depending on the year) payments or were discontinued from welfare but are still eligible because of the Edwards versus Kizer court order. Some welfare recipients are eligible only through the state (and not the federal) program. Aged, Blind, and Disabled group primarily consists of beneficiaries of the SSI program. Detailed data on eligibility categories are available from the California DHS publication, "Aid Codes Documentation."

Table 6B: \# of Observations for Welfare Recipients in the Sample

\begin{tabular}{|c|c|c|}
\hline \# Years & \# Recipients & \% of Total \\
\hline 1 & 60540 & $21.7 \%$ \\
\hline 2 & 51356 & $18.4 \%$ \\
\hline 3 & 35312 & $12.7 \%$ \\
\hline 4 & 26657 & $9.6 \%$ \\
\hline 5 & 23951 & $8.6 \%$ \\
\hline 6 & 19452 & $7.0 \%$ \\
\hline 7 & 61717 & $22.1 \%$ \\
\hline
\end{tabular}

Number of observations for individuals in the AFDC sample. \#Years $=t$ row provides the number of individuals who have $t$ years with at least one month of Medicaid eligibility as a welfare recipient from 1993-1999. 
Table 7A: The Effect of Mandates on Managed Care Enrollment Using Individual-Level Data

\begin{tabular}{|c|c|c|c|c|}
\hline \multirow{2}{*}{} & \multicolumn{3}{|c|}{ \% Eligible Months in Managed Care } \\
\cline { 2 - 5 } & $(1)$ & $(2)$ & $(3)$ & $(4)$ \\
\hline \% Mandated & .495 & .498 & .716 & .719 \\
& $(.053)$ & $(.053)$ & $(.057)$ & $(.058)$ \\
& {$[.076]$} & {$[.074]$} & {$[.060]$} & {$[.060]$} \\
\hline \% Mandated * Initial & & & -1.028 & -1.028 \\
& & & $(.151)$ & $(.159)$ \\
& & & {$[.118]$} & {$[.118]$} \\
\hline Eligible Months & .018 & .014 & .019 & .015 \\
& $(.002)$ & $(.002)$ & $(.002)$ & $(.002)$ \\
& {$[.003]$} & {$[.002]$} & {$[.003]$} & {$[.002]$} \\
\hline \# Observations & $1,044,302$ & $1,044,302$ & $1,044,302$ & $1,044,302$ \\
\hline R-squared & .758 & .762 & .775 & .779 \\
\hline Person \& Year Effects? & Yes & Yes & Yes & Yes \\
\hline Year Entry * Year Interactions? & No & Yes & No & Yes \\
\hline
\end{tabular}

Dependent variable is equal to the fraction of Medicaid eligible months in which the recipient is enrolled in a managed care plan. Standard errors in parentheses are clustered by county*year, while those reported in brackets are clustered by county to account for serial correlation in the error term. Regressions are weighted by the number of eligible months for the individual in the year.

Table 7B: Effect of Managed Care Enrollment on Medicaid Spending Using Individual-Level Data

\begin{tabular}{|c|c|c|c|c|c|c|}
\hline \multirow{2}{*}{ \% Managed Care } & \multicolumn{6}{|c|}{ Medicaid Spending for Individual j in Year t } \\
\cline { 2 - 7 } & $(1)$ & $(2)$ & $(3)$ & $(4)$ & $(5)$ & $(6)$ \\
\hline & & & 105.6 & 90.3 & 182.9 & 171.3 \\
& & & $(53.2)$ & $(52.4)$ & $(34.7)$ & $(33.7)$ \\
& & & {$[74.4]$} & {$[79.5]$} & {$[39.2]$} & {$[39.6]$} \\
\hline \% Mandated & 52.2 & 138.1 & & & & \\
& $(26.4)$ & $(22.7)$ & & & & \\
\hline Mandated * Initial & {$[36.8]$} & {$[26.7]$} & & & & \\
& & -399.6 & & & & \\
\hline Eligible Months & 72.7 & 73.2 & 70.9 & 78.4 & 69.4 & 77.0 \\
& $(1.4)$ & $(1.4)$ & $(1.9)$ & $(2.3)$ & $(1.5)$ & $(1.9)$ \\
& {$[1.3]$} & {$[1.3]$} & {$[1.6]$} & {$[2.3]$} & {$[1.3]$} & {$[1.6]$} \\
\hline \# Observations & $1,044,302$ & $1,044,302$ & $1,044,302$ & $1,044,302$ & $1,044,302$ & $1,044,302$ \\
\hline R-squared & .497 & .497 & - & - & - & - \\
\hline Person \& Year Effects? & Yes & Yes & Yes & Yes & Yes & Yes \\
\hline Yr Entry * Yr Interact? & No & No & No & Yes & No & Yes \\
\hline IV Used & - & - & 1 & 1 & $1 \& 2$ & $1 \& 2$ \\
\hline
\end{tabular}

Dependent variable is equal to total Medicaid expenditures for the individual in the year. Standard errors in parentheses are clustered by county*year, while those reported in brackets are clustered by county to account for serial correlation in the error term. Regressions are weighted by the number of eligible months for the individual in the year. 
Table 7C: Effect of Mandates on Managed Care Enrollment and Individual Medicaid Spending

\begin{tabular}{|c|c|c|c|c|c|c|}
\hline \multirow{2}{*}{} & \multicolumn{3}{|c|}{ \% Managed Care } & \multicolumn{3}{|c|}{ Medicaid Spending for Individual $\mathrm{j}$ in Year t } \\
\cline { 2 - 7 } & $(1)$ & $(2)$ & $(3)$ & $(4)$ & $(5)$ & $(6)$ \\
\hline \% Managed Care in & & & & & 155.6 & 192.2 \\
COHS Counties & & & & & $(36.0)$ & $(30.4)$ \\
& & & & & {$[48.2]$} & {$[35.8]$} \\
\hline \% Managed Care in & & & & & $(56.1$ & 165.6 \\
2-Plan, GMC Counties & & & & & {$[84.5]$} & {$[42.5]$} \\
\hline \% COHS Mandated & .795 & .931 & 130.2 & 185.0 & & \\
& $(.042)$ & $(.047)$ & $(29.4)$ & $(30.6)$ & & \\
\hline \% 2-Plan, GMC & {$[.039]$} & {$[.039]$} & {$[39.1]$} & {$[28.6]$} & & \\
Mandated & .458 & .674 & 34.8 & 121.2 & & \\
& $(.052)$ & $(.058)$ & $(26.0)$ & $(21.8)$ & & \\
\hline \% Mandated * Initial & {$[.070]$} & {$[.054]$} & {$[39.0]$} & {$[26.2]$} & & \\
& & -.968 & & -387.4 & & \\
& & $(.163)$ & & $(66.7)$ & & \\
\hline Eligible Months & .014 & .015 & 79.7 & 80.1 & 78.6 & 77.2 \\
& $(.002)$ & $(.002)$ & $(1.9)$ & $(1.9)$ & $(2.4)$ & $(2.0)$ \\
& {$[.002]$} & {$[.002]$} & {$[1.6]$} & {$[1.6]$} & {$[2.4]$} & {$[1.7]$} \\
\hline \# Observations & $1,044,302$ & $1,044,302$ & $1,044,302$ & $1,044,302$ & $1,044,302$ & $1,044,302$ \\
\hline R-squared & .767 & .782 & .497 & .497 & - & - \\
\hline Person \& Year Effects? & Yes & Yes & Yes & Yes & Yes & Yes \\
\hline Yr Entry * Yr Interact? & Yes & Yes & Yes & Yes & Yes & Yes \\
\hline IV Used & - & - & - & - & 1 & $1 \& 2$ \\
\hline Dep \&
\end{tabular}

Dependent variable is equal to Medicaid expenditures for the individual in the year. Standard errors in parentheses are clustered by county*year, while those reported in brackets are clustered by county to account for serial correlation in the error term. Regressions are weighted by the number of eligible months for the individual in the year.

Table 7D: Summary Statistics for Individual-Level Regressions

\begin{tabular}{|c|c|c|}
\hline & Mean & Std. Dev. \\
\hline Medicaid Spending & 766 & 2534 \\
\hline \% Managed Care & .360 & .444 \\
\hline \% Mandated & .392 & .468 \\
\hline \% Mandated * Initial & .085 & .141 \\
\hline Eligible Months & 9.8 & 3.5 \\
\hline \% COHS Mandated & .053 & .299 \\
\hline \% Two-Plan, GMC Mandated & .339 & .455 \\
\hline
\end{tabular}


Table 8A: IV Estimates of Effect of Managed Care Enrollment on Child Hospitalizations

\begin{tabular}{|c|c|c|c|c|}
\hline \multirow{2}{*}{} & \multicolumn{2}{|c|}{ Log (Avoidable Hospitalizations) } & \multicolumn{2}{c|}{ Log (Accidents \& Adverse Effects) } \\
\cline { 2 - 5 } & Medicaid & All & Medicaid & All \\
\hline \multirow{2}{*}{ \% Managed Care } & -.329 & -.165 & -.294 & -.218 \\
& {$[.148]$} & {$[.112]$} & {$[.144]$} & {$[.113]$} \\
\hline Log(Eligible Months) & .479 & .376 & .404 & .345 \\
& {$[.083]$} & {$[.087]$} & {$[.053]$} & {$[.073]$} \\
\hline \% Hispanic & -.106 & -.073 & .290 & .123 \\
& {$[.180]$} & {$[.110]$} & {$[.219]$} & {$[.111]$} \\
\hline \% Black & .422 & .106 & .623 & .145 \\
& {$[.240]$} & {$[.152]$} & {$[.434]$} & {$[.227]$} \\
\hline \# Observations & 8662 & 10588 & 7794 & 10057 \\
\hline Year and Zipcode Effects? & Yes & Yes & Yes & Yes \\
\hline
\end{tabular}

Sample consists of zipcode-year observations for 1993-1999. Dependent variable in the first specification is equal to the log of the number of Medicaid insured children admitted to the hospital with an avoidable condition. The dependent variable in the third specification is equal to the log of the number of hospitalizations among children with external causes of injury. Standard errors are reported in brackets and are clustered by county to account for serial correlation in the error term. Regressions include zipcode and year fixed effects and are weighted by the number of Medicaid eligible children.

Table 8B: IV Estimates of Effect of Managed Care Enrollment on Infant Health Outcomes

\begin{tabular}{|c|c|c|c|c|c|c|}
\hline \multirow{2}{*}{} & \multicolumn{2}{|c|}{ Fraction LBW } & \multicolumn{2}{c|}{ Fraction Very LBW } & \multicolumn{2}{c|}{ Infant Mortality Rate } \\
\cline { 2 - 7 } & $(1)$ & $(2)$ & $(3)$ & $(4)$ & $(5)$ & $(6)$ \\
\hline \% Managed Care & .0012 & & .0014 & & .00017 & \\
& {$[.0022]$} & & {$[.0011]$} & & {$[.00067]$} & \\
\hline \% Managed Care * & & -.0005 & & -.0004 & & -.00055 \\
COHS County & & {$[.0022]$} & & {$[.0004]$} & & {$[.00046]$} \\
\hline \% Managed Care * & & .0014 & & .0014 & & .00018 \\
Two-Plan County & & {$[.0028]$} & & {$[.0015]$} & & {$[.00081]$} \\
\hline \% Managed Care * & & .0031 & & .0048 & & .00157 \\
GMC County & & {$[.0017]$} & & {$[.0008]$} & & {$[.00089]$} \\
\hline \% Hispanic & -.0076 & -.0076 & .0021 & .0021 & -.0036 & -.0036 \\
& {$[.0069]$} & {$[.0068]$} & {$[.0024]$} & {$[.0024]$} & {$[.0041]$} & {$[.0041]$} \\
\hline \% Black & .1609 & .1613 & .0580 & .0583 & .0088 & .0089 \\
& {$[.0816]$} & {$[.0818]$} & {$[.0258]$} & {$[.0261]$} & {$[.0039]$} & {$[.0039]$} \\
\hline \# Observations & 11833 & 11833 & 11833 & 11833 & 11833 & 11833 \\
\hline Year and Zip Effects? & Yes & Yes & Yes & Yes & Yes & Yes \\
\hline
\end{tabular}

Sample consists of zipcode-year observations for 1993-1999. Standard errors are reported in brackets and are clustered by county to account for serial correlation in the error term. Regressions include zipcode and year fixed effects and are weighted by the number of Medicaid eligible children. 
Table 8C: Summary Statistics

\begin{tabular}{|c|c|c|c|c|c|}
\hline Table 8A & Mean & Std. Dev. & Table 8B & Mean & Std. Dev. \\
\hline Log (MC Avoidable) & 3.50 & 1.16 & \% Infants Black & .093 & .121 \\
\hline Log (All Avoidable) & 4.13 & 1.01 & \% Infants Hispanic & .515 & .256 \\
\hline Log (MC External) & 2.76 & 1.04 & \% Man Care & .313 & .256 \\
\hline Log (All External) & 3.45 & 0.90 & \% Man Care * GMC & .051 & .163 \\
\hline Log (MC Eligible) & 7.65 & 1.10 & \% Man Care * COHS & .048 & .180 \\
\hline \% Hispanic & .509 & .256 & \% Man Care * Two-Plan & .212 & .234 \\
\hline \% Black & .146 & .162 & \% LBW & .064 & .020 \\
\hline & & & \% VLBW & .012 & .008 \\
\hline & & & Infant Mortality & .0066 & .0049 \\
\hline
\end{tabular}


Appendix Table 1:

IV Estimates of Effect of Managed Care Enrollment on Medicaid Expenditures

\begin{tabular}{|c|c|c|c|c|c|c|c|c|}
\hline & \multicolumn{3}{|c|}{ Spending per Eligible } & \multicolumn{3}{c|}{ Log(Spending per Eligible) } \\
\cline { 2 - 9 } & $(1)$ & $(2)$ & $(3)$ & $(4)$ & $(5)$ & $(6)$ & $(7)$ & $(8)$ \\
\hline \% Managed Care & 47 & 180 & 127 & 140 & .012 & .048 & .046 & .033 \\
& $(85)$ & $(101)$ & $(75)$ & $(87)$ & $(.036)$ & $(.048)$ & $(.031)$ & $(.042)$ \\
& {$[168]$} & {$[171]$} & {$[142]$} & {$[139]$} & {$[.072]$} & {$[.080]$} & {$[.061]$} & {$[.069]$} \\
\hline$\%$ ABD & 5602 & 8363 & 5592 & 8312 & 1.435 & 2.726 & 1.431 & 2.707 \\
& $(781)$ & $(898)$ & $(786)$ & $(865)$ & $(.348)$ & $(.333)$ & $(.350)$ & $(.318)$ \\
& {$[1294]$} & {$[1561]$} & {$[1310]$} & {$[1498]$} & {$[.599]$} & {$[.602]$} & {$[.609]$} & {$[.572]$} \\
\hline \# Observations & 464 & 464 & 464 & 464 & 464 & 464 & 464 & 464 \\
\hline County Trends? & No & Yes & No & Yes & No & Yes & No & Yes \\
\hline DSH \$ included? & No & No & No & No & No & No & No & No \\
\hline IV used & 1 & 1 & $1 \& 2$ & $1 \& 2$ & 1 & 1 & $1 \& 2$ & $1 \& 2$ \\
\hline
\end{tabular}

Sample includes county-year observations for California from 1993 to 2000 and, in contrast to Table 4B, excludes county-specific disproportionate share hospital payments. Dependent variable in the first four (last four) specifications is equal to (the log of) Medicaid spending (in 2000 dollars) per eligible. Specifications in columns 1,2,5,6 use \% Mandated as an IV, while those in the remaining four columns use both \% Mandated and \% Mandated * Initial. Robust standard errors are included in parentheses, and those reported in brackets are clustered by county to control for serial correlation in the error term. Regressions include county and year fixed effects and are weighted by the share of Medicaid eligible months in a year accounted for by each county.

Appendix Table 2: Rates Paid to Commercial Plans in Two-Plan Counties

\begin{tabular}{|c|c|c|c|c|}
\hline County & \% HMO Pre & Avg. Paid 95 & Rate 1999 & $\Delta \mathrm{P}$ \\
\hline Los Angeles & $40.2 \%$ & 81.21 & 77.75 & $-4 \%$ \\
\hline San Bernardino & $31.0 \%$ & 75.78 & 74.04 & $-2 \%$ \\
\hline Riverside & $30.5 \%$ & 67.49 & 75.91 & $+12 \%$ \\
\hline Contra Costa & $22.1 \%$ & 74.20 & 78.77 & $+6 \%$ \\
\hline San Francisco & $13.2 \%$ & 68.65 & 90.56 & $+32 \%$ \\
\hline Fresno & $5.2 \%$ & 60.41 & 75.14 & $+24 \%$ \\
\hline Alameda & $4.7 \%$ & 60.37 & 80.30 & $+33 \%$ \\
\hline Santa Clara & $4.4 \%$ & 61.00 & 89.09 & $+46 \%$ \\
\hline San Joaquin & $0.9 \%$ & 51.48 & 71.14 & $+38 \%$ \\
\hline Kern & $0.0 \%$ & 64.50 & 89.09 & $+23 \%$ \\
\hline Stanislaus & $0.0 \%$ & 53.50 & 69.95 & $+31 \%$ \\
\hline
\end{tabular}

Table includes information for two-plan counties. Second column is the percentage of Medicaid recipients eligible through welfare receipt enrolled in a managed care organization in the month before the mandate. Third column is equal to average monthly expenditures for Medicaid recipients on welfare in 1995 in 1999 dollars. Fourth column is the monthly rate paid to the commercial HMO in January of 1999. Final column equals the percentage increase from the average paid amount in 1995 to the commercial rate paid in 1999. 